IFN Working Paper No. 861, 2011

\title{
Commercialization, Renewal and Quality of Patents
}

Roger Svensson 


\title{
Commercialization, Renewal and Quality of Patents
}

\author{
Roger Svensson *
}

January 31,2011

Key words: Patents, renewal, commercialization, quality, commercialization modes, contract terms, survival models.

JEL Classification: O31, O34, L24.

\begin{abstract}
One of the major reasons why inventors are awarded patents by governments is they encourage R\&D investments and commercialization of inventions. If the patent holder commercializes his invention, he has stronger incentives to retain the patent. The purpose here is to empirically analyze the relationship between commercialization and the renewal of patents. At the same time, I take into account defensive patent strategies (e.g. deterring competitors from utilizing the patent) and pointedly ask if there are any third factors (quality of the patent) that affect the commercialization and renewal decisions. Using a detailed database of Swedish patents, I utilize a survival model to estimate how commercialization influences the patent renewal decision. Basic results show commercialization and defensive strategies increase the probability a patent will be renewed, but also that quality influences commercialization and renewal decisions. When controlling for endogenous commercialization decision, there is still a strong positive relationship between commercialization and renewal of patents. Thus, given the quality of the patent, if the owner decides to commercialize the patent on the margin, this leads to longer survival of the patent. With regard to commercialization modes, there is some evidence licensed patents and patents commercialized in original and new firms - but not acquired patents - survive longer than noncommercialized patents. Looking more closely at the contracts of acquired and licensed patents, contracts with both variable and fixed fees - but not contracts with either variable or fixed fees - survive longer than non-commercialized patents. However, the analysis about modes and contract terms does not take into account the endogeneity problem.

* Research Institute of Industrial Economics (IFN), P.O. Box 55665, SE-10215 Stockholm, Sweden; Email: roger.svensson@ifn.se ; Tel: + 46 - 8 - 66545 49; Fax: + 46 - 8 - 6654599.

The author would like to thank Marie Thursby, William Greene, Per Botolf Maurseth, Erik Mellander, Frédéric Delmar and Erik Lindqvist as well as the seminar participants at the EEA annual conference in Budapest, the EPIP conference in Maastricht, the Uddevalla Symposium and the Vaxholm Entrepreneurship workshop for constructive comments, and Jakob Eliasson for excellent research assistance. Financial support from the Torsten and Ragnar Söderberg's Foundation and the Gustaf Douglas Research Program on Entrepreneurship is gratefully acknowledged.
\end{abstract}




\section{Introduction}

A steady stream of inventions and innovations are necessary for economic growth. But in a free market technological spillovers cause underinvestment in $R \& D$. To solve this problem, a government can either subsidize private $R \& D$ or grant exclusive rights patents - to the technology creators. The motivation behind granting patents for inventions are thus transparent, aiming to: 1) give incentives to inventors to create and commercialize inventions and new technologies; 2) disclose, diffuse and standardize new technologies; and 3) facilitate contracts (licensing/ownership) between inventors and producers (Scotchmer 2006). In this view the inventor files and retains a patent to protect an invention that he himself commercializes or sells/licenses to somebody else. Without the patent the technology behind the invention would be free to use for anyone.

However, patents are often filed and retained for non-innovative purposes (Granstrand 1999, Cohen et al. 2000):

- Defending other related patents in the firm's patent portfolio (shadow patents).

- Preempting competitors from entering specific technological fields or patenting related inventions (patent fences).

- Building up portfolios of patents which can be traded or cross-licensed.

- Signaling investors prior to an initial public offering about the value of the firm.

- Defending the firm against litigation lawsuits.

The main purpose of the present study is to analyze how important the commercialization decision is for keeping (renewing) patents. ${ }^{1}$ But defensive patent strategies are also taken into account in the analysis, and possible background variables which might simultaneously affect commercialization and renewal decisions are explored. For example, one could expect that high quality patents would have a high probability of being both renewed for long periods and commercialized. In the literature, the renewal of patents is often seen as the best measure of the private value of patents (Pakes and Schankerman 1984). Thus, more valuable patents should survive for longer periods. A secondary purpose is to decompose the commercialization decision

\footnotetext{
${ }^{1}$ Commercialization here means the original owner of the patent has either: 1) sold the patent; 2) licensed the patent; 3) introduced a new product based on the patent on the market in his own, existing firm; or 4) introduced a new product on the market in his own, new firm. Thus, a minimum requirement is that the patent has generated some income to the owner. However, commercialization does not need to be profitable for the original owner. This definition is similar to those made in previous studies on the commercialization of patents; see e.g. Griliches (1990) and Morgan et al. (2001).
} 
into four different modes - 1) commercialization in the original firm or 2) in a new firm, 3) patent is licensed or 4) sold to an external firm - and then relate these to the patent renewal decision. Finally, I will look more closely at the contract terms of sold and licensed patents. Both variable and fixed fees can be included in such contracts, and the contract design will give different incentives to inventors and firms to make an effort during commercialization (see section 2.2).

The present study is exploratory in nature and applies both descriptive statistics and econometric analysis to the research questions above. I use a detailed data set of Swedish patents granted to small firms and individuals, based on a survey conducted in 2003 and 2004. The survey response rate was 80 percent. The data set includes information on if, when and how the patent was commercialized, the renewal pattern, patent quality indicators (forward citations), as well as the payment structure (variable and/or fixed fees) of acquired and licensed patents. The model and the statistical estimations are based on the assumption that more valuable patents are renewed for longer periods. This assumption has also been made in previous patent renewal studies (see e.g. Schankerman and Pakes 1986). I use a Cox survival model to analyze the determinants of patent renewal. It tests how different explanatory variables affect the probability of patents being renewed, and thereby indirectly determine patent values. The renewal decision here is an option to keep the patent. To the best of my knowledge, no previous study has related the commercialization and patent renewal decisions to each other - mainly due to a lack of data.

The paper is organized as follows. In section 2, previous studies are discussed. The data set is described in section 2, including summary statistics. The statistical survival models are outlined in section 3 . In section 4 , the explanatory variables are described. The results from the empirical estimations are presented in section 5 , and the final section draws general conclusions.

\section{Previous literature}

\subsection{Determinants of patent renewal}

Most previous studies analyzing renewal of patents have estimated the value distribution of patents (Griliches 1990, Pakes 1986, Schankerman and Pakes 1986). All of these studies assume more valuable patents are renewed for longer periods than less valuable ones. It is assumed owners only renew patents if it is economically profitable to do so. The percentage of renewed patents indicates how large a share of the patents 
have an economic value after a given number of years. Schankerman and Pakes (1986) estimate both the distribution of the patent values and their rate of depreciation. They show about half of the European patents continue to be renewed after 10 years, but only 10 percent are renewed during the entire statutory period. According to Griliches (1990), most patents have a low value that depreciates rapidly. Only a few patents have a very high value.

There are some studies that have analyzed determinants of patent renewal. Using American patent data, Serrano (2008) finds acquired patents have a higher probability of being renewed than non-acquired ones. Harhoff et al. (1999) show that German and U.S. patents that were renewed during the entire statutory period were cited more often than expired patents. They conclude patents with economic value get cited more often.

Maurseth (2005) is the only previous study to use a survival model to estimate how different factors influence patent renewal. Relying on an intuitive distinction between citations across and within technology fields, he finds patents which receive citations across fields survive longer than average, whereas those with citations within fields expire earlier. The interpretation is citations across technology fields indicate a scientific breakthrough, whereas citations within fields indicate many competing patents.

With regard to patent renewal studies, Maurseth (2005) is the most closely related paper to the study at hand, since both use survival model estimations. However, they differ in several key respects. First, Maurseth's study is based on a data set of Norwegian patents granted by the European Patent Office (EPO), while this paper is concerned with data on Swedish patents. Second, whereas Maurseth studies patent citations, in addition to patent citations I analyze different commercialization variables. And finally, the empirical model specification has been improved, taking into account that a granted patent cannot expire until it has been granted.

\subsection{Incentives to include variable and fixed fees}

When a patent is licensed or acquired, further inventor cooperation might be required during commercialization. Most inventions need to be adapted to market conditions before commercialization and the necessary technical knowledge might be the inventor's private information. By engaging the inventors, ex post, the external firm also avoids competing with possible follow-up inventions from the inventors. Jensen and Thursby (2001) conclude many licensed university inventions are so embryonic that 
continued engagement by inventors is necessary for 71 percent of the licensed inventions. I argue here that further cooperation by the inventors is needed for inventions in general in assuring commercialization. Braunerhjelm and Svensson (2010) found inventors play an active role in 87 percent of all commercialized patents originating from small firms and individuals.

Jensen and Thursby (2001) point out that when licensing contracts rely uniquely on fixed fees (upfront or annual fees) there is a moral hazard problem with regard to inventor effort. For the external firm, licensing with royalty payments is therefore preferable. Royalties link the inventor's license income to the external firm's output, the performance of the invention, and hence to inventor effort. This moral hazard problem also applies to acquired patents. ${ }^{2}$

When acquisition and licensing contracts rely uniquely on variable fees (and hence lack fixed fees) there is another moral hazard problem (Dechenaux et al. 2009). Commercialization requires investment by the external firm, but the firm's true agenda is private information and concealed from the inventor. For example, the licensee may intentionally "shelve" the invention for strategic reasons, in an attempt to block competing firms from developing the invention, or to protect other existing patents of the licensee. The shelving may also be unintentional if the firm realizes the expected profits are lower than the firm's required rate of return at any stage of development. By including fixed (upfront or annual) fees in the contract, Dechenaux et al. (2009) show the external firm has an incentive to commercialize the invention, and hence signals its intentions to the inventor.

One would expect acquired/licensed patents with contracts including both variable and fixed fees to perform better ex post than patents with contracts that rely uniquely on either variable or fixed fees. Both inventors and the external firm then have incentives to make an effort during commercialization. Heretofore this hypothesis has not been tested empirically. ${ }^{3}$

\footnotetext{
${ }^{2}$ In principle, if contracts could be complete there would be no difference between licensing and acquisition (Tirole 1988). Consequently, I focus on different payment terms when analyzing the contracts, rather than on the distinction between licensing and acquisition.

${ }^{3}$ A closely related study is Dechenaux et al. (2008), who investigate different factors affecting the commercialization decision of licensed university inventions, using a model based on optimal stopping. They use a Hazard model to estimate the determinants of when the licensee decides to terminate the license, commercialize the invention or delay the commercialization. They claim the importance of lead times induces the licensee to delay the commercialization until they have developed the product. On the other hand, patent scope and learning increase the probability of commercialization. The Hazard of terminating a license decreases with the effectiveness of patent strength and secrecy. However,
} 
There are also other reasons to include variable and fixed fees in the contracts. If the future sales of a particular invention are highly uncertain, including variable fees is a way to share risks and profits between the licensor and licensee. The licensee will then avoid high payments in the case of a bad invention (Bosquet et al. 1998). Another argument is based on asymmetric information. If the inventor has private information about the invention, then he can signal confidence of its presumed high value by offering a contract which relies heavily on royalties. In the event the invention is not good, this requires low payments (Gallini and Wright 1990, Kamien 1992). This argument about signaling is important since it establishes the perception the contract terms might well depend on the quality of the invention and thus are endogenous. A contract with only fixed fees is justified by the fact that royalties increase marginal costs of using the invention, and consequently suppresses the amount the licensee is willing to pay to the licensor (Kamien et al. 1992). Also, the licensor may simply prefer fixed fees, as this eliminates the need to monitor the licensee's output.

\section{Database and descriptive statistics}

I use a detailed data set on patents granted to small firms (less than 1000 employees) and individual inventors. ${ }^{4}$ The data set is based on a survey conducted in 2003-04 on Swedish patents granted in 1998. In that year, 1082 patents were granted to Swedish small firms and individuals. ${ }^{5}$ The sample selection is not a problem, as long as the conclusions are drawn for small firms and individuals located in Sweden. Information about inventors, applying firms and their addresses as well as application dates for each

\footnotetext{
Dechenaux et al. (2008) present no information on the payment structure of the licensing contracts. My study complements their research by relating terms of payment to patent renewal.

${ }^{4}$ All inventions do not result in patents. However, since an invention that does not result in a patent is seldom registered anywhere, there are two basic problems with empirically analyzing the invention or innovation (commercialized invention) rather than the patent. First, it is difficult to find these new ideas, products and developments among all the firms and individuals, whereas all patents are registered. Second, even if the inventions are found, it is difficult to judge whether they are sufficient improvements to qualify as inventions. Only the national and international patent offices make such judgements. Therefore, focusing on patents rather than all inventions is inherently much easier for an empirical study of the commercialization process. However, the CIS database on innovations in the EU is an exception to this rule, since it covers both patented and unpatented innovations (CIS 2010).

${ }^{5}$ In 1998, 2760 patents were granted in Sweden. 776 of these were granted to foreign firms, 902 to large Swedish firms with more than 1000 employees, and 1082 to Swedish individuals or firms with less than 1000 employees. In a pilot survey carried out in 2002, it turned out large Swedish firms refused to provide information on individual patents. Furthermore, it proved very difficult to persuade foreign firms to answer fill-in questionnaires about patents. These firms are almost always large multinationals firms.
} 
patent, was received from the Swedish Patent and Registration Office (PRV). Thereafter, a questionnaire was sent out to the inventors of the patents. ${ }^{6}$

The questionnaire asked the inventors about the work place where the invention was created, if and when the invention had been commercialized, which kind of commercialization mode was chosen, and whether the contract terms of the licensed and acquired patents included variable and/or fixed fees, etc. 867 (out of 1082) inventors filled in and returned the questionnaire, i.e., the response rate was 80 percent. The falling off is not systematic with respect to IPC-classes or regions. ${ }^{7}$ The response rate is satisfactorily high, given that such a database has seldom been collected before and inventors or applying firms normally consider information about inventions and patents confidential. The data set was later complemented with data on patent renewal and forward citations from the Espacenet (2010) website.

In Sweden, patent owners must pay an annual renewal fee to PRV to keep their patents in force. The patent expires if the renewal fee is not paid in any single year,. Thus, the patent owner every year has an option to renew the patent. A patent can only expire at a fixed date every year, on the anniversary of the original application date. In 1999, the size of the renewal fees was increasing annually, ranging from 200 SEK in the first year to 4300 SEK in the last year, adding up to total of about 35000 SEK over 20 years. ${ }^{8}$ The Swedish renewal fees are modest compared to those for EPO and American patents (van Pottelsberghe and Francois 2009). ${ }^{9}$

The commercialization and survival rates of the 867 patents by firm size are described in Table 1. 408 patents (47 percent of the sample) were granted to individuals,

\footnotetext{
${ }^{6}$ Each patent always has at least one inventor and often an applying firm as well. The inventors or the applying firm can be the owner of the patent, but the inventors can also own the patent indirectly, via the applying firm. Sometimes, the inventors are only employed in the applying firm, which owns the patent. If the patent had more than one inventor, the questionnaire was sent to only one of the inventors.

${ }^{7}$ Of the $20 \%$ non-respondents, $10 \%$ of the inventors had old addresses, $5 \%$ had correct addresses but none responded, and the remaining 5\% refused to participate. The only information we have about the non-respondents is the IPC-class of the patent and the region of the inventors. For these variables, there was no systematic difference between respondents and non-respondents.

${ }^{8}$ In 1999, the annual fees for the 20 years in ascending order were: 200, 250, 350, 550, 700, 900, 1100 , 1350, 1 600, 1 900, 2 250, 2 500, 2 700, 2 850, 3 050, 3 300, 3 550, 3 800, 4050 and 4300 SEK.

${ }^{9}$ According to Van Pottelsberghe and Francois (2009), the total cost for a patent which is renewed for 20 years is EUR 120000 (40 000) in 13 (3) EPO member states, EUR 14500 in the U.S. and EUR 17300 in Japan. High costs include procedural costs (official costs up to the grant date) and external services that the inventor/firm needs when filing the patent. EPO patents are much more expensive due to high translation costs - the granted patent must be translated and validated in each targeted national patent office. The other reason why EPO patents are more expensive is higher annual renewal fees (which vary with the duration of the protection). The authors show that renewal fees for 20 years in the EPO system are EUR 89000 (22 000) in 13 (3) member states, whereas this cost is considerably lower in the U.S. and Japan. However, the renewal fees in a single European country like Sweden are of a modest amount.
} 
and 116, 201 and 142 patents were granted to medium-sized firms (101-1000 employees), small firms (11-100 employees) and micro companies (2-10 employees), respectively. ${ }^{10}$ The commercialization rate for the whole sample is 61 percent. ${ }^{11}$ The commercialization rate for the firms ranges from 66 to 74 percent, in contrast to the rate of 51 percent for individuals. A contingency-table test indicates a statistically significant difference between the commercialization rates of firms and individuals. The chi-square value is 30.6 (with 3 d.f.), significant at the one percent level. The survival rate is increasing with the firm size, rising from 44 percent for individuals to 76 percent for medium-sized firms. A contingency-table test indicates a statistically significant difference between firm size categories. The chi-square value is 46.7 (with 3 d.f.), significant at the one percent level.

\section{[Table 1]}

Table 2 compares commercialized and renewed patents. As expected, patents still alive in 2004 (71 percent) have been commercialized to a higher degree than expired ones (48 percent). The chi-square test shows the independence of commercialization and renewal can be rejected. However, 35 percent (186 of 526) of the commercialized patents have already expired. This is due either to the products having a short lifecycle or failed commercialization. 42 percent (142 of 341) of the noncommercialized patents were alive in 2004. If most of these patents were defensive, with the purpose of defending existing patents, then the owner should have more similar granted patents. Among the commercialized patents in our database, 46 percent of the owners have at least one additional similar patent. Among the non-commercialized patents, this percentage is only 33 percent. If the patent had not been commercialized, the inventor was asked why the patent had not been commercialized. Among the 341 non-commercialized patents, only 15 inventors listed shadow-patenting as one of the

\footnotetext{
${ }^{10}$ The group of individual inventors includes private persons, self-employed inventors as well as twothree inventors, who are organized in trading companies or private firms without employees.

${ }^{11}$ This rate should be compared to the few available studies which have measured commercialization of patents: 47 percent for American patents found by Morgan et al. (2001) and 55 percent in the studies surveyed by Griliches (1990). ${ }^{11}$ The higher commercialization rate in the present study is explained by the fact that only patents owned by small firms and inventors are included - large (multinational) firms have many more defensive patents. Griliches (1990) confirms this view and reports the commercialization rate is 71 percent for small firms and inventors.
} 
reasons why the patent had not been commercialized. ${ }^{12}$ I draw the conclusion that retaining patents for strategic reasons is not common among individuals and small firms; this strategy is more frequent among large multinational firms.

[Table 2]

In Table 3, the commercialization and renewal decisions are related to the quality of patents, measured as the number of forward citations to the patents or their patent equivalents from the application date to November 2007 (excluding self-citations). In the literature, forward citations are seen as the most reliable measurement of patent quality, since it shows how important the patent is for subsequent patents and inventions. Almost $60 \%$ of the patents ( 517 of 867 ) in the data set have no forward citations at all, indicating a low value. Moreover, just $5 \%$ (45 of 867) have more than 5 forward citations. By testing differences between means, it turns out both the commercialization and renewal decisions are positively related to forward citations. For example, commercialized patents have 1.39 citations on average in contrast to 0.95 for non-commercialized patents - and the difference is statistically significant. However, the patents have different application dates, implying patents with early application dates should be more frequently cited. Therefore, the number of forward citations per patent is measured per five-year period (in the bottom of Table 3), but this does not alter the results between groups. A similar pattern can be observed for both for patents still alive in 2004 and expired ones. The former group has more citations per patent and the differences between the groups are even more obvious. The results of Table 3 indicate it is not unlikely that the high quality of the patent is an important explanation to both the commercialization and renewal decisions. Thus, a part of the positive relationship between commercialization and renewal in Table 2 can be explained by a third underlying variable - the quality of the patent.

\section{[Table 3]}

\footnotetext{
12 The most frequent reasons here were: 1) problems with financing (115 patents); 2) problems with marketing (75 patents); 3) problems in finding a manufacturing firm/licensor (74 patents); and 4) the product is not yet ready for commercialization (62 patents). Note that inventors may have mentioned more than one reason why the patent was not commercialized.
} 
Table 4 shows how the patents were commercialized across firm groups. Most patents were commercialized within the firm that created the invention, hereafter called the original firm. In 71 cases, a new firm based on the patent was set up, while 46 patents were licensed and 19 were sold. None of the medium-sized firms used external commercialization (licensing or selling) as their first choice. The smaller the firm size, the higher the probability that the patent was sold or licensed. This result is in line with Serrano (2008), who found individual inventors and small firms sell their patents more often than large firms do. New firms are almost exclusively started by individual inventors in our sample.

However, the patent owner can later decide to change the mode of commercialization. As shown in the lower part of Table 4, this occurs for 47 patents in our sample - most of which were first commercialized in the original firm. In this second round the pattern is quite different and external commercialization dominates, especially through selling the patent. In total, 56 patents were sold and 52 were licensed. 75 patents were commercialized in new firms, which constitute 14 percent of all commercialized patents. This is a somewhat higher level than for American patents, for which around 10 percent of all patents are commercialized in new firms (AUTM 1998).

[Table 4]

Table 5 describes the renewal pattern across modes of commercialization. For each mode, it is shown how many patents were still alive in 2004 and had expired. As many as 43 percent of the acquired patents had expired, in contrast to 35 percent for licensed patents and 30-34 percent for patents commercialized in original or new firms. By looking more closely at expired patents, it turns out acquired patents on average survive less than three years after they have been acquired. The other groups of patents survive around four years after they have been commercialized. Thus, acquired patents expire with a higher probability. Given that they will expire, they expire faster measured from the commercialization time point compared to patents associated with other modes of commercialization. In the lower part of the table the average number of citations per patent across commercialization modes is shown. Licensed patents have considerably more citations than the other modes, but the differences are not significant, due in part to the low number of observations in each group. 
[Table 5]

The upper part of Table 6 displays basic information on the payment structure of acquired and licensed patents. An overwhelming majority (48 patents) of the acquired patents include only a fixed fee, while the remaining eight involve both fixed and variable fees. By contrast, 30 licensed patents include both royalty payments linked to the turnover of the licensee and fixed fees (upfront or annual fees), while the remaining 22 licensing contracts include only royalty payments.

In the middle part of Table 6 , it turns out that acquired/licensed patents with variable or fixed fees expire more frequently (46 percent) and survive for a shorter time (3.2 years), given that they expire, compared to those with both variable and fixed fees (26 percent and 3.7 years). This result is in line with the hypothesis that moral hazard problems with regard to commercialization effort arise if either variable or fixed fees are excluded from the acquisition/licensing contract. In the lower part of Table 6, forward citations indicate the quality of contracts with both variable and fixed fees is somewhat higher than for contracts with either variable or fixed fees, but the difference is not significant.

[Table 6]

\section{Theoretical background and statistical models}

\subsection{Theoretical background}

Pakes and Schankerman (1984) have presented a model based on the assumption more valuable patents are renewed for longer periods. The patent owner must pay an annual renewal fee, $C_{a j}$, to keep the patent in force. This fee varies with age $a$ and cohort $j$ of the patent. ${ }^{13}$ The patent owner who pays the renewal fee earns the current implicit return to patent protection during the coming year, $R_{a j}$. Schankerman (1998) assumes that the pattern of $R_{a j}$ is known with certainty when the patent is applied for. If the owner does not pay the fee, the patent expires permanently and thereafter its returns are zero. The owner's decision problem is then to maximize the discounted value of net returns by choosing the age at which to stop paying the renewal fee. Therefore, the owner chooses a lifetime, $T$, in order to solve the problem: ${ }^{14}$

\footnotetext{
${ }^{13}$ All patents applied for in the same year belong to the same cohort.

${ }^{14}$ Since Swedish patents can only expire at fixed annual dates, discrete time is used. Maurseth (2005) uses a model with continuous time, similar to that with discrete time.
} 


$$
V(T)=\max _{T \leq M} \sum_{a=1}^{T} r^{a}\left(R_{a j}-C_{a j}\right)
$$

where $V$ is the value of patent protection given the optimal renewal decision, $r$ is the discount factor and $M$ is the statutory limit of patent protection (20 years). Provided that the path of net revenues $\left(R_{a j}-C_{a j}\right)$ is non-increasing in age, the optimal rule for the owner is to renew the patent as long as the revenues cover the renewal costs, i.e. as long as $R_{a j} \geq C_{a j}{ }^{15}$ When the net returns become negative, the owner should stop payment. If no such time point exists, the patent should be kept for the maximum life span (T=M). Thus, the renewal decision is an optimal stopping problem and the patents can be seen as options. The initial returns in a given cohort, $R_{0 j}$, are allowed to vary across patents, but decay at the same rate, $\delta_{a j}$. Thus, $R_{t+1}=\delta R_{t}$. If all patents in a cohort had the same initial returns and path of revenues, they would expire at the same age. Schankerman (1998) shows the survival function of patents can be written as a function of unknown parameters.

\subsection{Main statistical model}

Since the analysis focuses on an event (expiration of patents) to occur, survival (duration) analysis is used in the statistical estimations. The event in question is if and when the patent expires. First, I estimate a survival distribution function and a hazard function of the renewal pattern. ${ }^{16}$

In the main empirical analysis, I estimate how different explanatory factors (e.g. commercialization decision, patent quality, firm size, etc.) affect the decision to let the patents expire. The dependent variable, $E X P T_{i}$, is a random variable showing how many years it takes until patent $i$ expires, measured from the time point of patent application. ${ }^{17}$ Patents that have not yet expired in 2004 - the end point of observation - are "rightcensored" (480 observations). The other 387 patents expired in 2004 at the latest. Given this, the appropriate statistical model is the Cox (1972) proportional hazard model:

\footnotetext{
${ }^{15}$ The renewal fees are non-decreasing in age. A sufficient condition for the net revenues to be nonincreasing in age is that the path of revenues, $R_{a j}$, is non-increasing in age.

${ }^{16}$ The survival function, $S(t)$, shows how a large share of the patents survives beyond a time point, $t$. The hazard function, $h(t)$, shows the conditional probability of a patent expiring in a specific time period $\Delta t$, given that it has survived (not expired) until time point $t$. The hazard can also be expressed as a function of the probability density function, $f(t)$, and the survival function: $h(t)=f(t) / S(t)$.

${ }^{17}$ The application year is the standard starting time point to use. Information on the application year is directly available from the Swedish National Patent Office (PRV).
} 


$$
\log h_{i}(E X P T)=\log \lambda_{0}(t)+x_{i 1} \beta+x_{i 2}(t) \gamma,
$$

where $\log \lambda_{0}(t)$ is a baseline hazard function, $t$ is the time in years, $\boldsymbol{\beta}$ and $\boldsymbol{\gamma}$ are vectors of parameters to be estimated, $\mathbf{x}_{\mathbf{1}}$ is a vector of time independent explanatory variables, and $\mathbf{x}_{2}(\mathbf{t})$ is a vector of time dependent explanatory variables. ${ }^{18}$ The proportional hazard assumption of the model means the covariates multiply hazard. The effect of an explanatory variable $x_{k}$ may, for example, halve the hazard of expiration at any time $t$.

A patent obviously cannot expire until it has been granted, and thus is not in the risk set prior to this time point. If the owner had not paid the renewal fee for an applied patent before the patent was granted, the invention would neither have been granted a patent nor have been included in the data set. Therefore, I remove the patent from the risk set between the origin (application date) and the time point for granting patents. This procedure is called left truncation. ${ }^{19}$ This is a valuable methodological extension beyond Maurseth (2005), who did not take this into account.

An advantage with the Cox model compared to the alternative statistical model of accelerated failure time (see Allison 1995) is that time dependent explanatory variables can be included in the estimations. The present study exploits this and includes the time point of different commercialization modes of the patent since the mode can change over time. Another advantage of the Cox model is that there is no need to choose between different residual distributions. Thus, the baseline hazard function, $\log \lambda_{0}(t)$, can be left unspecified. Finally, the Cox model makes it possible to interpret the quantitative effects in terms of how an increase in the explanatory variable affects the hazard ratio.

\subsection{Endogeneity and extended statistical models}

The commercialization decision will be included as an explanatory variable in equation (2). If the patent owner commercializes the patent, then he should have stronger incentives to keep the patent, as suggested in the introduction. However, an evident

\footnotetext{
${ }^{18}$ The measurement of the number of years is an exact measure, since the owner must every year pay a renewal fee prior to the anniversary date of the original patent application. I therefore use a discrete approximation of the Cox model to account for the fact that two or more events may occur at the same point in time (Allison 1995).

${ }^{19}$ This is accomplished by defining a time-dependent covariate whose values are missing at times when the patent is not in the risk set. In practice this means patents will get a starting year of 1997 and the first possible year of expiration is then 1998. Using the grant year as the starting year in the model is not appropriate, since some of the time-dependent explanatory variables (in particular, those associated with the commercialization decision) change values between the application and the grant dates.
} 
problem is both the commercialization and renewal decisions are taken by the patent owner. Thus, the commercialization decision is likely endogenous.

This raises the question of whether there is a reverse causality between renewal and commercialization. I argue here this is not likely the case, since the commercialization always starts before the patent expires - if both these events occur. In fact, there is not a single observation in the data set where a patent that already has expired is commercialized. It is rather that the expiration decision sets the limit for determining if a patent can be commercialized or not. If a patent filed in 1994 expires in 2002 it cannot then be commercialized after this year. Instead, I argue the quality of the patent will drive the commercialization and renewal decision in the same direction - as indicated by the descriptive statistics in Table 3.

In the extended econometrical analysis, I will start with estimating how patent quality and other explanatory variables affect the commercialization decision, since this decision is likely endogenous. Also, the commercialization decision is an event. It can occur directly after the patent has been filed. The variable $C O M T_{i}$ shows how many years it takes until commercialization starts for patent $i$, measured from the time point of application date. Patents that have not yet been commercialized in 2003 are "rightcensored" (337 observations). Furthermore, an expired patent cannot be commercialized. If the patent is not yet commercialized and expires before 2004, the patent is right-censored in this expiration year. 199 patents are right-censored before 2003 due to expiration and 138 at the end point of observation. Measurement of the starting point of commercialization in years is a rather rough measure. Therefore, COMT is "interval-censored" for the commercialized patents (530 observations). ${ }^{20}$ Since interval-censored observations are included, the accelerated failure time (AFT) model is the appropriate statistical model (Allison 1995):

$$
\log \left(C O M T_{i}\right)=z_{i} \alpha+\sigma \varepsilon_{i}
$$

where $\varepsilon$ is a random disturbance term, $\boldsymbol{\alpha}$ is a vector of parameters and $\sigma$ is a parameter to be estimated, and $\mathbf{z}$ is a vector of explanatory variables. The $\varepsilon$ 's can have various

\footnotetext{
${ }^{20}$ If the patent is commercialized within the first year, $T$ obtains an interval-censored value between 0.1 and 1 , while the second year $T$ is between 1.1 and 2 , etc.
} 
distributions, corresponding to different AFT-models, e.g. the log-normal, log-logistic, exponential, Weibull and gamma models. ${ }^{21}$

To take account of the fact that when analyzing the renewal decision the commercialization decision is likely endogenous, I use an instrument variable technique. In the first step, an ordinary probit model is estimated to explain the decision to commercialize the patent or not. The dependent variable COM is then a dummy variable, which equals 1 if the patent is commercialized and 0 otherwise:

$$
F^{-1}\left(P_{i}\right)=z_{i} \delta
$$

where $P_{i}$ is the estimated probability that the patent is commercialized. $F^{-1}$ is the inverse of the cumulative normal distribution function, $\mathbf{z}$ is the same vector of explanatory variables as in equation (3) and $\boldsymbol{\delta}$ is a vector of parameters. In the second step, the predicted value of $C O M$ is then included in the main Cox equation (2). An alternative would be to estimate a survival model in the first step (equation 3), to take into account the timing of the commercialization decision. However, such a statistical instrument variable technique with two succeeding survival equations in both the first and second steps has not yet been developed.

\section{Explanatory variables}

\subsection{Main variables}

The explanatory variables consist of factors that are expected to affect, or be correlated with, the probability that a patent is renewed or left to expire. Patents that are commercialized or retained for defensive purposes are expected to survive longer than others (see introduction). Table 7 reports basic statistics on several explanatory factors. Hypotheses are shown only for the main variables. A negative (positive) expected parameter estimate means the hazard rate of letting the patent expire decreases (increases) when the explanatory variable obtains a higher value.

[Table 7]

The fact that a patent is commercialized will alternatively be included as a timedependent or a time-independent dummy. For example, the timing of commercialization

\footnotetext{
${ }^{21}$ All these models will be run in the empirical part. Using likelihood-ratio tests, it is possible to decide which of the models best fits the data.
} 
may be important for the renewal decision if the product, based on the patent, has a fixed life-time. ${ }^{22}$ The commercialization decision is then represented by a timedependent additive dummy, COMT, which takes on a value of 1 once the commercialization has started, and 0 otherwise. Alternatively, the commercialization decision signals, but does not change the nature of the patented idea. This could be the case if the quality of the patent explains both the commercialization and survival of the patent. COM is then measured as an additive dummy that takes on the value of 1 if the patent is commercialized, and 0 otherwise. The expected impact on the hazard of expiration is negative for both COMT and COM.

The commercialization mode can be used instead of COMT. There are four main commercialization modes in the data set: acquired patents, licensed patents, commercialization of the patent in the original firm or commercialization in a new firm. These are represented by the four time-dependent additive dummies COMACQT, COMLICT, COMORIGT and COMNEWT, which equal 1 when the associated commercialization mode starts and retain this value as long as the mode is present, and 0 otherwise. If the mode of commercialization changes, which occurs in a total of 47 cases (see Table 2), the dummy variables also change values. In both cases, the commercialization mode is expected to have a negative impact on the hazard of letting the patent expire. Thus, these patents should survive longer than non-commercialized patents. As in the case of $C O M$, the mode variables will also be specified as additive (time-independent) dummies, measuring the first commercialization mode: COMACQ, COMLIC, COMORIG and COMNEW. The disadvantage of these variables is of course that they do not take account of the fact the mode may change over time.

As shown in Table 6, acquired and licensed patents can instead be expressed as variables based on the contract terms. If the contract includes both variable and fixed fees the time-dependent additive dummy ALVandFT equals 1 , and 0 otherwise. Contracts with either variable or fixed fees are represented by the time-dependent dummy ALVorFT. These variables equal 1 when the contract starts and retain this value as long as the contract is in force, and 0 otherwise. In line with the prior discussion, it is reasonable to expect $A L V a n d F T$ to have a stronger negative impact on the hazard than

\footnotetext{
${ }^{22}$ Imagine the case of a new product based on a patent, which has an expected life-time of five years. After the fifth year, the owner lets the patent expire. The timing of the start of commercialization will then be decisive for how long a time the patent survives.
} 
$A L \operatorname{VorFT}$, since the former group of contracts provides incentives for inventors and the external firm to exert effort during commercialization.

In addition, a test is made of the performance of patents with contracts relying uniquely on variable fees and on fixed fees. The goal is to find out if it is the lack of fixed fees or the lack of variable fees which cause the possible failure of the external commercialization, and hence that the patent expires. ALonlyVT is a time dependent dummy which equals 1 when the licensing/acquisition contract including only variable fees starts and retains this value as long as the contract is in force, and 0 otherwise. Similarly, the time dependent dummy ALonlyVT takes on the value 1 for contracts with only fixed fees. ALonlyVT and ALonlyFT substitute for ALVorFT. I predict ALVandFT has a stronger negative impact on the hazard than both ALonlyVT and ALonlyFT.

Keeping a patent for defensive purposes is the second main explanatory factor for the renewal decision, after commercialization. The additive dummy $D E F$ equals 1 if the patent is not commercialized but retained as a defensive patent, and 0 otherwise. The expected impact on the hazard is negative, i.e. defensive patents should survive longer than other non-commercialized patents. When interpreting the hazard ratios of the commercialization variables and $D E F$, the reference group is always noncommercialized non-defensive patents. ${ }^{23}$

As an indicator of the quality of the patent, $Q U A L$ measures the total number of forward citations a patent and its patent equivalents have received during a five year period (as was used in section 3). ${ }^{24}$ Self-citations are excluded. In the literature this kind of citation variable has been interpreted as an indicator of the quality of patents, and is expected to have a negative relationship to the hazard. ${ }^{25}$

\footnotetext{
${ }^{23}$ Since a patent cannot take on the value of 1 for both $D E F$ and $C O M$, the hazard ratio for $D E F$ will show the impact on the hazard compared to the reference group of other non-commercialized patents. By the same logic, the hazard ratio of $C O M$ will show the difference in hazards between commercialized and non-commercialized non-defensive patents.

${ }^{24}$ A patent equivalent is the same patent granted at a different patent office, e.g. EPO, USPTO. A patent which has a late application date on average will be cited fewer times than a patent with an early application date. Therefore, the citations in the present study are weighted by the number of days from the application date until November 2007.

${ }^{25}$ Trajtenberg (1990) shows that forward citations indicate the social value of patents. The more frequently a patent is cited by later patents, the higher is the spillover effect and hence the social value of the cited patent. In the literature, forward citations have frequently been used as a measure of patent quality or value, even though there is often skepticism about whether forward citations really measure patent value and / or spillover effects (Hall et al. 2007). A patent can be cited any time after the application date, even after it has expired.
} 


\subsection{Control variables}

Control variables that may be correlated with the renewal scheme are included to test for robustness. Firms and individuals may have different resources and patterns for renewing their patents, so additive dummies for different firm sizes are also included. FIRM1 is a dummy that takes on the value 1 for medium-sized firms with 101-1000 employees, 0 otherwise. FIRM2 equals 1 for small firms with 11-100 employees, 0 otherwise. Finally, FIRM3 takes on the value 1 for micro companies with 2-10 employees, 0 otherwise. The firm group dummies relate here to the reference group of the individual inventors.

The additive dummy UNIV equals 1 for university patents, and 0 otherwise. SIMILAR is an additive dummy, which equals 1 if the inventors or applying firm have other similar patents in the same technology area, and 0 otherwise. The variable $I N V N M B R$ measures the number of inventors of the patent at hand. Some specific characteristics of the inventors are also included in the model. SEX measures the percentage of inventors who are female. It might represent the generalization that women are more or less risk aversive than men. ETH measures the percentage of inventors who belong to ethnic minorities, i.e. immigrants from regions other than Western Europe. Many immigrants have difficulty landing a stable job in Sweden, implying that they may have different commercialization and renewal strategies than others.

Different technologies are likely to be associated with different risks. Consequently, the probability of a patent expiring depends on the type of technology. Patents are divided into 30 technology categories by Breschi et al. (2004), groups based on the patents' main IPC-Class. ${ }^{26}$ The data is divided into six different kinds of regions according to NUTEK (1998): Large city regions, university regions, regions with important primary city centers, regions with secondary city centers, small regions with private employment, and small regions with government employment. Five additive dummies are included in the estimations for these six groups. Additive dummies are also included for different application periods, to control for economic shocks that may affect all patents in a given application period. The data has five application year

\footnotetext{
${ }^{26}$ All technology categories are not represented in the data set, and some categories have inadequate observations. Given this circumstance, only 26 categories and 25 additive dummies are used in the present study. Technology classes with too few observations are merged with other closely related classes (Breschi et al. 2004).
} 
periods (1985-90, 1991-92, 1993-94, 1995-96 and 1997-98) and four additive dummies are assigned for these periods. ${ }^{27}$

Most of the explanatory variables described above are also included when estimating the commercialization decision in equations 3 and 4. Some additional variables, earlier found to be correlated with the commercialization decision in Svensson (2007), are included as instruments. The dummy KOMPL takes on the value of 1 if complementary patents are needed for commercialization, and 0 otherwise. GOVFIN measures how large a portion of the patent's R\&D-costs (in percent) was financed through government capital. A positive correlation with time until commercialization starts is expected. The variable PRIVFIN shows the percent of the $R \& D$ costs that were financed through external private venture capital. There is also a third kind of external financing. OTHERFIN measures how large a portion of the R\&D costs was financed through universities and research foundations.

\section{Empirical estimations}

\subsection{Survival and Hazard functions}

Figure 1 shows the survival and hazard functions of the renewal decision, estimated by the Life-table method (Allison 1995). Since patents are not at risk of expiring until they have been granted, the patent grant year is normalized to 0 . Year 1 is the first possible year when the patent can expire. ${ }^{28}$ The survival function for all patents is declining from the outset, and declines increasingly faster with each passing year. The corresponding hazard function has an increasing trend. ${ }^{29}$ When dividing the sample on commercialized and non-commercialized patents, the former group has a higher survival rate. Both LogRank and Wilcoxon tests show the difference is clearly significant at the 1-percent level.

\section{[Figure 1]}

\footnotetext{
${ }^{27}$ Time dummies for individual application years were also used, but within this specification one of the models failed to converge. Instead, I used time dummies for two-year periods. The usage of two-year periods does not alter the results for the other estimated parameters. Note that only one patent was applied for in 1985 and in 1986, respectively, and no patents were applied for during the 1987-89 period. Therefore, 1985, 1986 and 1990 have been merged into a single group.

28 The starting year is set to either 1997 or 1998, depending on whether the grant date occurs before or after the annual renewal (application) date. Left-truncation is not possible when using the Life-table method.

${ }^{29}$ The survival and hazard functions are less reliable for the seventh year, since none of the patents starting in 1998 have a seventh year.
} 
Similar survival and hazard functions divided on cited and non-cited patents are depicted in Figure 2. Here, cited patents have a higher survival rate than non-cited ones, and Log-Rank and Wilcoxon tests show the difference is significant at the 1-percent level. This supports the view patents with high quality tend to survive for longer periods.

[Figure 2]

\subsection{Basic Cox proportional hazard estimations}

The results of the basic Cox survival model estimations are shown in Table 8. In order to test for robustness, several model specifications are estimated. In Model I, $Q U A L$ is included, but neither COMT nor DEF. In Model II, COMT and DEF are included but not QUAL. In Model III, all three main variables are included. As expected, all three variables have a negative and significant impact on the hazard. The size interpretation of the parameter estimate is that the hazard of expiration for commercialized patents is only 52 percent of the hazard for non-commercialized patents (excluding defensive patents). The hazard of expiration for defensive patents is only $24-27$ percent of the hazard for other non-commercialized patents (in Models II-V). This is a stronger impact than that of commercialized patents. However, it is important to bear in mind that in this data set the number of commercialized patents exceeds those used as defensive patents in the dataset. Finally, the interpretation of $Q U A L$ is that one more forward citation during a five year period is associated with a 14 percent decrease of the hazard.

What is even more interesting is that eliminating any of the main variables in Models I or II, compared to Model III, does not alter the significance levels or the hazard ratios. If COMT is endogenously determined by $Q U A L$, one would expect the estimated parameters of COMT should change when $Q U A L$ is added or removed from the model (compare Models II and III). But it does not, which is an indication that endogenous interdependence between the main variables (EXPT, COMT and QUAL) is not a great problem in the estimations. The next section will further examine this problem. Substituting COMT for COM in Models IV and V gives similar results. There are only minor changes in significance levels and hazard ratios, compared to Models II and III. Given these contrasts, it seems that specifying the commercialization decision as a time-independent or time-dependent dummy makes little sense. 
All firm size dummies have a negative and significant impact on the hazard of expiration. The larger the firm, the lower the probability that patents are left to expire. If the patent is owned by a medium-sized firm (FIRM1), a small firm (FIRM2) or a micro company (FIRM3), the hazard of expiration is around 76, 54 and 38 percent lower, respectively, than the hazard for patents owned by individuals (Model III). This finding is not surprising, since large firms have more resources and capabilities to exploit their patents, and also may be better able to judge their downstream potential profitability.

The only other significant control variable is $O W N E R$, which also reduces the patent's hazard of expiration. If the inventor's ownership of the patent increases by 1 percent, then the hazard of expiration decreases by 0.6 percent. This result raises questions about the accuracy of the signal when a patent is owned by its inventor for a long period of time. This duration might mean the patent is useful. On the other hand, one can readily imagine a psychological bias on behalf of inventors. External firms may have an easier time letting the patent expire, whereas inventors may cling onto the patent in the hope/belief of having come up with an important invention. The results for the control variables are robust, as they are for later estimations (Tables 10-12). An attempt to include additive dummies for unique owners (firms/inventors) in the estimations did not yield results due to multicollinearity problems. ${ }^{30}$

\subsection{Extensions with endogenous commercialization decision}

An objection against the model specification in the former section would be that both decisions of renewal and commercialization are taken by the owner, and thus could be endogenously determined by other factors in the model, as discussed above. I start by estimating how the commercialization decision depends on the quality of the patent and other factors. The specification of the AFT-model in Model VI in Table 9 builds on Svensson (2007), but here I add $Q U A L$ as an explanatory variable. Three different variants of Model VI are estimated, including different combinations of technology and region dummies. A negative (positive) parameter estimate in the AFT-model means an

\footnotetext{
${ }^{30}$ Among the 867 patents in the sample, there are 740 unique owners (firms/inventors). 663 owners have only one commercialized patent in 1998, 54 owners have two patents, and only 23 owners have at least three patents. Dummies can only be assigned to the 54 owners with at least 2 patents. However, with the dummies for unique owners included, the models were characterized by severe multicollinearity problems with very large standard errors for these owner dummies. These problems persisted even after excluding all technology and region dummies and when dummies were included only for those 23 owners with at least three patents.
} 
increase in the explanatory variable causes the commercialization decision to occur faster (slower), and thus increases (decreases) the probability of commercialization. A goodness-of-fit test showed that the log-logistic distribution of the residuals was an appropriate choice of the AFT-model.

The results show that if $Q U A L$ is high commercialization occurs faster. If a patent receives an additional citation during a five year period in Model VI-c, commercialization occurs 32 percent faster. ${ }^{31}$ Since the AFT-model is not a proportional hazard model, a quantitative interpretation of the estimated parameters can only be made in terms of survival time. The results of the other explanatory variables are almost identical to those in Svensson (2007), where FIRM2, FIRM3, UNIV, STATFIN and KOMPL exert significant impacts on COMT.

[Table 9]

An alternative specification is to estimate the commercialization decision as a pure dummy decision, and using a probit model as shown in Model VII. Here a positive (negative) parameter estimate implies that an increase in the explanatory variable increases (decreases) the probability the patent is commercialized. With respect to the significance levels of the estimated parameters of the explanatory variables, there are only minor differences between Models VI and VII. One more forward citation of the patent during a five year period is associated with an increase of the probability of commercialization with 4.3 percent units in Model VII-c. Of the estimations in Table 9, it is only in Model VI-a when technology dummies are excluded that $Q U A L$ does not exert any significant impact on COMT.

In Table 10, I have estimated a two-step model with instrument variable technique for COM, as described in section 4.3. When using instrument variable technique, the estimation results are usually sensitive to what kinds of instruments are chosen. Therefore, it is preferable to have many different instruments. The financing variables, $K O M P L$ and $Q U A L$ are alternatively used as instruments.

[Table 10]

\footnotetext{
${ }^{31}$ The quantitative interpretation of the effect of the explanatory variables (also dummies) on survival time proceeds as follows: If the explanatory variable increases by 1 unit, the survival time changes by $100\left(\mathrm{e}^{\beta}-1\right) \%$.
} 
Compared to the basic Cox estimations in Table 8, there are some differences. First, the predicted value of $C O M-\operatorname{pred}(C O M)$ - have a larger effect on the hazard (hazard ratio of 0.11-0.16 instead of 0.52), but is less significant as the standard errors increase. The latter feature is common for instrumented variables. The parameter estimate of $\operatorname{pred}(C O M)$ is insignificant in Model X (although the Hazard ratio is as low as 0.32 ), but then only one instrument is used (KOMPL). Otherwise, the hazard ratios of $\operatorname{pred}(C O M)$ are relatively robust - especially when many instruments are used (Models VIII, IX and XII). Second, the significant impacts of $Q U A L$ and $D E F$ on the renewal decision in the Cox equation disappear. Thus, it seems like the quality of the patent affecting the renewal decision via COM.

The interpretation of the two-step estimations is as follows. Given the quality, commercialization of the patent gives the owner stronger incentives to retain the patent, as the product based on the patent needs protection. This is also one of the basic reasons why governments grant patents.

\subsection{Different commercialization modes}

In Table 11, the commercialization variable is divided into different commercialization modes. When using time-dependent dummies in Models XIII and XIV, all modes except COMACQT have a significant and negative impact on the hazard. Thus, acquired patents do not survive significantly longer than non-commercialized ones. The hazard of expiration for patents that are licensed, commercialized in original firms and commercialized in new firms, respectively, is 50,52 and 44 percent of the hazard for non-commercialized patents (that are not defensive patents).

[Table 11]

If measuring the mode variables as usual dummies instead in Models XVI and XVII, all modes have a negative and significant impact on the hazard. A drawback of these estimations is that they only take account of the first commercialization choice. In the case of acquisitions, only 19 of 56 acquisitions are considered (see Table 4), since the commercialization mode may change over time. Furthermore, different modes of commercialization start at different time points measured from the application date. Commercialization in the original firm starts on average 1.3 years after the application 
date, commercialization in a new firm after 2.1 years, licensing after 2.3 years and acquisition after 3.9 years. This clear pattern suggests time-dependent dummies are the appropriate way to measure the commercialization mode.

Turn now to the endogeneity problem of the commercialization mode variables. When only one variable $(C O M)$ is endogenous and needs to be instrumented, it is not impossible to handle the problem, as seen in the former section. However, here four variables (COMACQ, COMLIC, COMORIG and COMNEW) need to be explained in a first step (equation 4) by almost the same explanatory variables. The predicted dummy variables should then be inserted in equation (2). Such a two-step estimation would simply collapse.

In such a situation, the most feasible robustness test I can undertake is to remove variables from the Cox model that likely determine the commercialization mode. $Q U A L$ is such an explanatory variable, as well as firm size dummies. Table 4 shows the commercialization mode is strongly related to firm size. Removing $Q U A L$ in Models XIII and XVI does not alter the significance levels or hazard ratios of the mode variables. When the firm size dummies are removed in Model $\mathrm{XV}$, the results for the mode variables barely change.

\subsection{Different contract terms of acquired and licensed patents}

In Models XVIII-XXI (Table 12), the effects of acquired/licensed patents with both variable and fixed fees (ALVandFT), and those with either variable or fixed fees $(A L V o r F T)$ on the hazard are shown. As expected, ALVandFT has a negative and significant impact on the hazard of patent expiration. Combining variable and fixed fees provides incentives to both inventors and the external firm to exert effort during the commercialization process. The risk of expiration decreases by about 61 percent for ALVandFT compared to non-commercialized patents (Model XVIII), However, ALVorFT does not appear to have any significant effect whatsoever on the hazard. This suggest patents whose contracts include both variable and fixed fees have a better chance of renewal and in the long run commercial success. Although the hazard ratio between ALVandFT and ALVorFT is relatively large (around 0.50), the difference is only significant at the 10-percent level in two of four models (Models XVIII and 
XXI). ${ }^{32}$ Thus, there is no conclusive evidence that it is better to include in the contracts both variable and fixed fees, rather than either variable or fixed fees.

[Table 12]

Similar Cox estimations, in which acquired/licensed patents with only variable fees $(A L o n l y V T)$ and only fixed fees (ALonlyFT) are substituted for (ALVorFT), are shown in Models XXII and XXIII. Neither ALonlyVT nor ALonlyFT alone have any statistically significant impact on the hazard of patent expiration. Furthermore, the difference between their parameter estimates and the parameter estimate of ALVandFT is never statistically significant. Estimations here with time-independent dummies of the contract variables are rather pointless, as we would lose 43 acquired/licensed patents (out of 108) that have changed commercialization mode (see Table 4).

However, as the earlier discussion of commercialization modes point out, the contract terms are likely endogenously determined by $Q U A L$ and other variables in the model. For example, if there are problems with asymmetric information between the patent owner and the external firm, the patent owner can signal high quality of the patent by offering a contract that includes variable fees (Gallini and Wright 1990, Kamien 1992). Thus, the contracts terms should depend on the quality of the patent. The results of Table 12 should therefore be taken with a degree of caution.

To instrument all the commercialization variables (ALVandFT, ALVorFT, COMORIGT and COMNEWT) in a first step in similar ways simply does not work. The best I can do is to remove variables that likely determine the contract terms and observe how the other parameters are affected. QUAL is removed in Models XIX and XXIII, but the results for $A L V a n d F T$ and $A L V o r F T$ are hardly impacted at all. In Models XX and $\mathrm{XXI}$, the firm dummies and other control variables are removed, but the results for the main variables are still robust.

\section{Concluding remarks}

One of the main reasons why governments award patents to inventors is to encourage $R \& D$ investments and commercialization of inventions. Other reasons are to disclose and diffuse new knowledge, and facilitate licensing and ownership contracts of

\footnotetext{
${ }^{32}$ It is likely that this lack of statistical significance is due to the small sample size. ALVandFT and ALVorFT equal 1 for only 37 and 66 observations, respectively.
} 
knowledge. If the patent owner commercializes his invention, then he has stronger incentives to hold on to the patent. However, inventors also file and retain patents for defensive, non-innovative reasons such as protecting other similar patents or deterring competitors from utilizing the invention. The purpose of the present study was to empirically analyze the relationship between commercialization and renewal of patents. At the same time, I sought to take into account defensive strategies for keeping patents and if a third factor like quality of the patent affects the commercialization and renewal decisions in the same direction. To the best of my knowledge this report breaks new ground in empirically investigating how the commercialization decision is related to the renewal decision for patents.

To estimate the renewal of patents a detailed database on Swedish patents owned by individuals and small firms was used. Basic results show that commercialization and defensive strategies increase the probability that the patent is renewed. The hazard of patent expiration for commercialized patents is 48 percent lower than the hazard for non-commercialized patents. Moreover, pure defensive patents reduce the hazard of patent expiration by more than 70 percent compared to other non-commercialized patents. However, there are only a small number of defensive patents in the sample. This suggests commercialization rather than defensive strategies matters the most for patent renewal, at least among small firms and individual inventors. But the results also show that the quality of the patent influences the commercialization and renewal decisions in the same direction. Thus, the commercialization decision is likely endogenous in the model.

When controlling for endogenous commercialization decision by using instrument variable techniques, there is still a strong positive relationship between commercialization and renewal of patents. In fact, the negative impact of commercialization on the hazard of expiration is then even stronger (now 80-85 percent lower than for non-commercialized patents), but the significance level diminishes somewhat. Thus, given the quality of the patent, if the owner decides to commercialize the patent on the margin, this is associated with a longer duration of the patent.

With regard to commercialization modes, there is some evidence that licensed patents and those commercialized in original and new firms - but not acquired patents survive longer than non-commercialized patents. Looking more closely at the contracts of acquired and licensed patents, it seems like contracts with both variable and fixed fees - but not contracts with either variable or fixed fees - survive longer than non- 
commercialized patents. This is in line with previous theoretical studies, though none of them empirically tested the generalization. The intuition here is that both the inventor and the external firm have incentives to make an effort during commercialization when the contract includes both fees. Excluding any of the fees causes moral hazard problems. However, the analysis about commercialization modes and contract terms does not take into account the endogeneity problem, meaning a cautious attitude to the latter results is wise.

A fundamental limitation of the present study is that the data set only included patents owned by small firms and individuals. Defensive patent strategies are undoubtedly applied far more frequently by larger firms. This should be investigated in future research where data is available. The estimates are also based on Swedish patents, but there is no obvious reason to suspect that if data had been used from another country the results would differ. It is probable a data set with patents owned by large firms would impact the results more than the country of origin of the patent owners.

Another important limitation is that the empirical analysis of how commercialization modes and contract terms relate to the renewal decision suffers from endogeneity problems. For example, the licensor can signal a high value of the patent by offering a contract which relies heavily on variable fees and thus requires low fixed payments if the patent is useless. Thus, the contract terms would be a function of the quality of the patent. However, this is not at all easy to get a handle on inasmuch as several (at least four) variables need to be instrumented in a similar way. This is a complex puzzle to solve in future work.

\section{References}

Allison, P.D. 1995. Survival Analysis Using SAS - A Practical Guide. Cary, NC: SAS Institute Inc.

Association of University Technology Managers. 1998. AUTM Licensing Survey. Norwalk, CT: Association of Technology Managers.

Bosquet, A., H. Cremer, M. Ivaldi and M. Wolkowicz. 1998. Risk Sharing in Licensing. International Journal of Industrial Organization 16: 535-54.

Braunerhjelm, P. and R. Svensson. 2010. The Inventor's Role: Was Schumpeter Right? Journal of Evolutionary Economics 20: 413-44.

Breschi, S., F. Lissoni and F. Malerba. 2004. The Empirical Assessment of Firms' Technological Coherence: Data and Methodology. In The Economics and Management 
of Technological Diversification, ed. J. Cantwell, A. Gambardella and O. Granstrand, 69-98. London: Routledge.

CIS. 2010. Community Innovation Studies (CIS). http://epp.eurostat.ec.europa.eu/ portal/page/portal/microdata/cis

Cohen, W.M., R.R. Nelson, and J.P. Walsh, J.P. 2000. Protecting Their Intellectual Assets: Appropriability Conditions and Why U.S. Manufacturing Firms Patent (or Not). NBER Working paper No. 7552. Cambridge, Ma: NBER.

Cox, D.R. 1972. Regression Models and Life Tables. Journal of Royal Statistical Society: B34: 187-220.

Dechenaux, E., B. Goldfarb, S. Shane and M. Thursby. 2008. Appropriability and Commercialization: Evidence from MIT Inventions. Management Science 54: 893-906.

Dechenaux, E., M. Thursby and J. Thursby. 2009. Shirking, Sharing Risk and Shelving: The Role of University License Contracts. International Journal of Industrial Organization 27: 80-91.

Espacenet. 2010. Espacenet patent database.

http://se.espacenet.com/search97cgi/s97_cgi.exe?Action=FormGen\&Template=se/SE/h ome.hts

Gallini, N.T. and B.D. Wright. 1990. Technology Transfer under Asymmetric Information. RAND Journal of Economics 21: 147-160.

Granstrand, O. 1999. The Economics and Management of Intellectual Property: Towards Intellectual Capital. Cheltenham, U.K., and Northampton, Ma: Edward Elgar.

Griliches, Z. 1990. Patent Statistics as Economic Indicators: A Survey. Journal of Economic Literature 28: 1661-1707.

Hall, B.H., G. Thoma and S. Torrisi. 2007. The Market Value of Patents and R\&D: Evidence from European firms. NBER Working paper No. 13426. Cambridge, Ma: NBER.

Harhoff, D., F. Narin, F.M. Scherer and K. Vopel. 1999. Citation Frequency and the Value of Patented Citations. Review of Economics and Statistics 81: 511-15.

Jensen, R. and M. Thursby. 2001. Proofs and Prototypes for Sale: The Licensing of University Inventions. American Economic Review 91: 240-59.

Kamien, M.I. 1992. Patent Licensing. In Handbook of Game Theory, ed. R.J. Aumann and S. Hart, 331-55. Amsterdam: Elsevier.

Kamien, M.I., S.S. Oren and Y. Tauman. 1992. Optimal Licensing of Cost-Reducing Innovation. Journal of Mathematical Economics 21: 483-508. 
Maurseth, P.B. 2005. Lovely but Dangerous: The Impact of Patent Citations on Patent Renewal. Economics of Innovation and New Technology 14: 351-74.

Morgan, R.P., C. Kruytbosch and N. Kannankutty. 2001. Patenting and Invention Activity of U.S. Scientists and Engineers in the Academic Sector: Comparisons with Industry. Journal of Technology Transfer 26: 173-83.

NUTEK. 1998. Småföretag och regioner i Sverige 1998 - Med ett tillväxtperspektiv för hela landet. Rapport B1998:10. Stockholm: NUTEK.

Pakes, A. 1986. Patents as Options: Some Estimates of the Value of Holding European Patent Stocks. Econometrica 54: 755-84.

Pakes, A. and M. Schankerman. 1984. The Rate of Obsolescence of Patents, Research Gestation Lags, and the Private Rate of Return to Research Resources. In R\&D, Patents and Productivity, ed. Z. Griliches, 98-112. Chicago: Chicago University Press.

Schankerman, M. 1998. How Valuable is Patent Protection? Estimates by Technology Field. RAND Journal of Economics 29: 77-107.

Schankerman, M. and A. Pakes. 1986. Estimates of the Value of Patent Rights in European Countries during the Post-1950 Period. Economic Journal 96: 1052-76.

Scotchmer, S. 2006. Innovation and Incentives. Cambridge, Ma: MIT Press.

Serrano, C.J. 2008. The Dynamics of the Transfer and Renewal of Patents. NBER Working paper No. 13938. Cambridge, Ma: NBER.

Svensson, R. 2007. Commercialization of Patents and External Financing during the R\&D-Phase. Research Policy 36: 1052-69.

Tirole, J. 1988. The Theory of Industrial Organization. Cambridge, Ma: MIT Press.

Trajtenberg, M. 1990. A Penny for Your Quotes, Patent Citations and the Value of Innovations. RAND Journal of Economics 21: 172-187.

Van Pottelsberghe, B. and D. Francois. 2009. The Cost Factor in Patent Systems. Journal of Industry, Competition and Trade 9: 329-55. 
Figure 1. Survival and Hazard functions for the renewal of commercialized and non-commercialized patents.

Share/probability

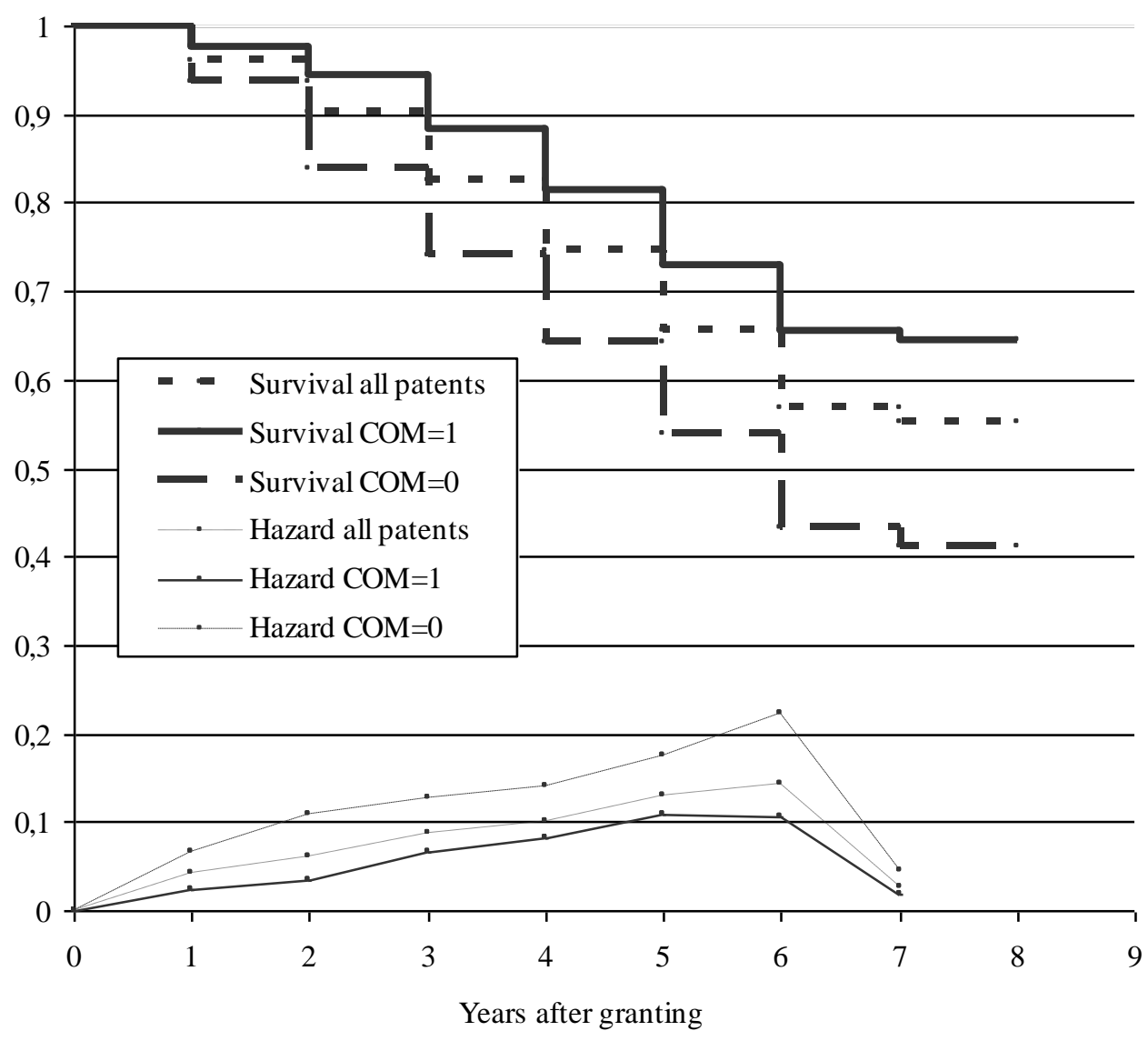


Figur 2. Survival and Hazard functions for the renewal of cited and non-cited patents

Share/probability

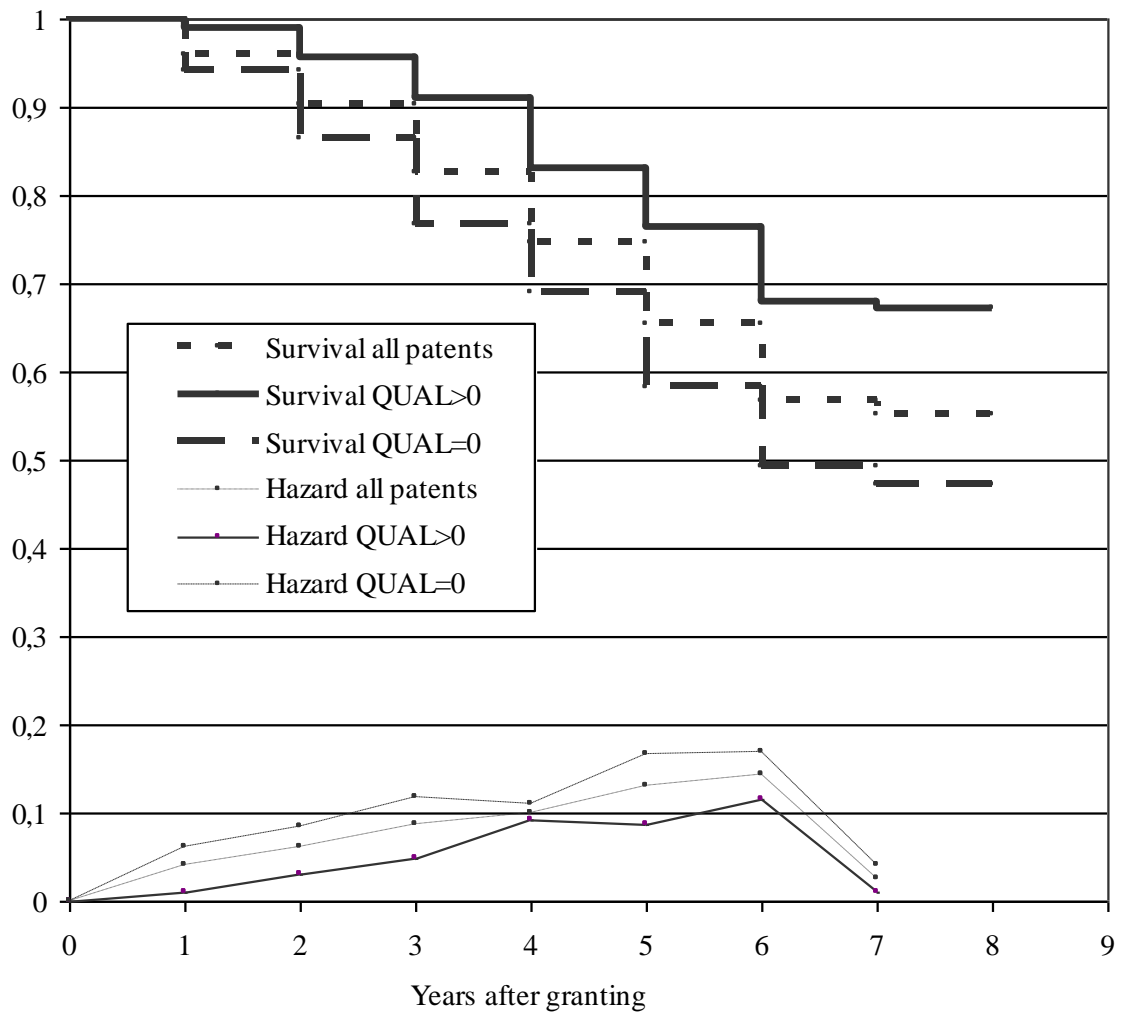


Table 1. Commercialization and renewal of patents across firm sizes. Number of patents and percent.

\begin{tabular}{lccc}
\hline \hline Kind of firm where invention was created & $\begin{array}{c}\text { Total number } \\
\text { of patents }\end{array}$ & $\begin{array}{c}\text { Percent latest } \\
\text { commercialized } \\
\text { in 2003 }\end{array}$ & $\begin{array}{c}\text { Percent } \\
\text { renewed in } \\
2004\end{array}$ \\
\hline \hline Medium-sized firms (101-1000 employees) & 116 & $66 \%$ & $76 \%$ \\
\cline { 2 - 4 } $\begin{array}{l}\text { Small firms (11-100 employees) } \\
\text { Micro companies (2-10 employees) }\end{array}$ & 201 & $68 \%$ & $63 \%$ \\
\cline { 2 - 4 } Individuals (1-4 inventors) & 142 & $74 \%$ & $61 \%$ \\
\hline \hline Total & $\mathbf{8 6 7}$ & $\mathbf{6 1 \%}$ & $\mathbf{5 6 \%} \%$ \\
\hline
\end{tabular}

Table 2. Commercialized patents and patents still alive in 2004. Number of patents and percent

\begin{tabular}{lcccc}
\hline \hline \multirow{2}{*}{ Patents still alive in 2004 } & \multicolumn{2}{c}{ Patents latest commercialized in 2003 } & Percent \\
\cline { 2 - 4 } & Yes & No & Total & $71 \%$ \\
\hline \hline Yes & 340 & 142 & 482 & $48 \%$ \\
No & 186 & 199 & 385 & $61 \%$ \\
\hline \hline Total & 526 & 341 & 867 & \\
\hline Percent still alive & $65 \%$ & $42 \%$ & $56 \%$ &
\end{tabular}

Note: Chi-square-value is 44.32 , significant at the 1 percent level for 1 d.f.

Table 3. Forward citations, commercialization and renewal. Number of patents.

\begin{tabular}{|c|c|c|c|c|c|}
\hline \multirow[b]{2}{*}{ No. of forward citations } & \multicolumn{2}{|c|}{$\begin{array}{c}\text { Patents latest } \\
\text { commercialized in } 2003\end{array}$} & \multicolumn{2}{|c|}{ Patents still alive in 2004} & \multirow[t]{2}{*}{ Total } \\
\hline & Yes & No & Yes & No & \\
\hline 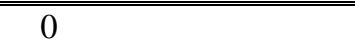 & 284 & 233 & 246 & 271 & 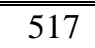 \\
\hline 1 & 95 & 48 & 94 & 49 & 143 \\
\hline 2 & 49 & 17 & 45 & 21 & 66 \\
\hline 3 & 30 & 13 & 29 & 14 & 43 \\
\hline 4 & 23 & 10 & 23 & 10 & 33 \\
\hline 5 & 13 & 7 & 17 & 3 & 20 \\
\hline 6 & 7 & 4 & 6 & 5 & 11 \\
\hline 7 & 8 & 1 & 5 & 4 & 9 \\
\hline$>7$ & 17 & 8 & 17 & 8 & 25 \\
\hline Total & 526 & 341 & 482 & 385 & 867 \\
\hline $\begin{array}{l}\text { No. of citations per } \\
\text { patent }\end{array}$ & 1.39 & 0.95 & 1.47 & 0.90 & 1.22 \\
\hline $\begin{array}{l}\text { Differences between } \\
\text { means, t-statistics }\end{array}$ & \multicolumn{2}{|c|}{$2.73 * * *$} & \multicolumn{2}{|c|}{$3.26 * * *$} & ------ \\
\hline $\begin{array}{l}\text { No. of citations per } \\
\text { patent and 5-year period }\end{array}$ & 0.57 & 0.39 & 0.61 & 0.36 & 0.50 \\
\hline $\begin{array}{l}\text { Differences between } \\
\text { means, t-statistics }\end{array}$ & \multicolumn{2}{|c|}{$2.72 * * *$} & \multicolumn{2}{|c|}{$4.72 * * *$} & ------ \\
\hline
\end{tabular}


Table 4. Commercialization mode across firm types. Number of patents.

\begin{tabular}{|c|c|c|c|c|c|}
\hline \multirow{2}{*}{$\begin{array}{l}\text { Kind of firm where the } \\
\text { invention was created }\end{array}$} & \multicolumn{4}{|c|}{ Commercialization mode - first choice } & \multirow{2}{*}{ Total } \\
\hline & Acquired & Licensing & Original firm & New firm & \\
\hline Medium-sized firms & 0 & 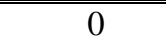 & 77 & 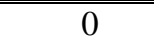 & 77 \\
\hline Small firms & 2 & 2 & 133 & 0 & 137 \\
\hline Micro companies & 4 & 7 & 93 & 1 & 105 \\
\hline Inventors & 13 & 37 & 87 & 70 & 207 \\
\hline Total & 19 & 46 & 390 & 71 & 526 \\
\hline \multirow[b]{2}{*}{$\begin{array}{l}\text { Kind of firm where the } \\
\text { invention was created }\end{array}$} & \multicolumn{4}{|c|}{ Commercialization mode - second choice } & \multirow[b]{2}{*}{ Total } \\
\hline & Acquired & Licensing & Original firm & New firm & \\
\hline Medium-sized firms & 4 & 0 & 0 & 1 & 5 \\
\hline Small firms & 8 & 0 & 0 & 1 & 9 \\
\hline Micro companies & 5 & 6 & 0 & 2 & 13 \\
\hline Inventors & 20 & 0 & 0 & 0 & 20 \\
\hline Total & 37 & 6 & 0 & 4 & 47 \\
\hline
\end{tabular}

Table 5. Renewal and quality of patents across modes of commercialization. Number of patents and forward citations, percent and years.

Commercialization mode

\begin{tabular}{|c|c|c|c|c|}
\hline & Acquired & Licensing & Original firm & New firm \\
\hline Still alive in 2004 & 32 & 34 & 272 & 49 \\
\hline Expired & 24 & 18 & 118 & 26 \\
\hline Total & 56 & 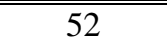 & 390 & 75 \\
\hline$\%$ expired & $43 \%$ & $35 \%$ & $30 \%$ & $35 \%$ \\
\hline Years until expired ${ }^{a}$ & 2.8 & 3.9 & 5.4 & 4.3 \\
\hline $\begin{array}{l}\text { No. of forward citations } \\
\text { per patent }\end{array}$ & 1.16 & 2.12 & 1.39 & 1.20 \\
\hline $\begin{array}{l}\text { Differences between } \\
\text { means, t-statistics }\end{array}$ & \multicolumn{4}{|c|}{ No significant difference between any two means } \\
\hline $\begin{array}{l}\text { No. of citations per } \\
\text { patent and 5-year period }\end{array}$ & 0.48 & 0.79 & 0.58 & 0.51 \\
\hline $\begin{array}{l}\text { Differences between } \\
\text { means, t-statistics }\end{array}$ & \multicolumn{4}{|c|}{ No significant difference between any two means } \\
\hline
\end{tabular}


Table 6. Renewal and quality of acquired and licensed patents with different contract terms. Number of patents and forward citations, percent and years.

Acquired/licensed patents with

\begin{tabular}{|c|c|c|c|c|}
\hline & $\begin{array}{c}\text { Fixed and } \\
\text { variable fees }\end{array}$ & $\begin{array}{c}\text { Fixed or } \\
\text { variable fees }\end{array}$ & Only fixed fees & Only variable fees \\
\hline Acquired & 8 & 48 & 48 & 0 \\
\hline Licensed & 30 & 22 & 0 & 22 \\
\hline Total & 38 & 70 & 48 & 22 \\
\hline Still alive in 2004 & 28 & 38 & 27 & 111 \\
\hline Expired & 10 & 32 & 21 & 11 \\
\hline Total & 38 & 70 & 48 & 22 \\
\hline$\%$ expired & $26 \%$ & $46 \%$ & $44 \%$ & $50 \%$ \\
\hline Years until expired ${ }^{a}$ & 3.7 & 3.2 & 2.9 & 3.7 \\
\hline $\begin{array}{l}\text { No. of forward citations } \\
\text { per patent }\end{array}$ & 1.73 & 1.54 & 0.98 & 2.73 \\
\hline $\begin{array}{l}\text { Differences between } \\
\text { means, t-statistics }\end{array}$ & \multicolumn{2}{|c|}{0.25} & $\begin{array}{ll}---- \\
---\end{array}$ & ---- \\
\hline $\begin{array}{l}\text { No. of citations per } \\
\text { patent and 5-year period }\end{array}$ & 0.70 & 0.59 & 0.41 & 0.95 \\
\hline $\begin{array}{l}\text { Differences between } \\
\text { means, t-statistics }\end{array}$ & \multicolumn{2}{|c|}{0.44} & ---- & $\begin{array}{ll}--- \\
---\end{array}$ \\
\hline
\end{tabular}

Note: The column with fixed or variable fees is a sum of the last two columns. Self-citations are excluded from forward citations. Forward citations are measured from the application date to November 2007.

${ }^{a}$ Measured from the date of commercialization and given that the patent has expired. 
Table 7. Descriptive statistics and hypotheses for the explanatory variables.

\begin{tabular}{|c|c|c|c|c|}
\hline Denotation & Description & Mean & $\begin{array}{l}\text { Std. } \\
\text { dev. }\end{array}$ & $\begin{array}{l}\text { Expected impact } \\
\text { on hazard }\end{array}$ \\
\hline$Q U A L$ & $\begin{array}{l}\text { Number of forward citations that the patent has received per five- } \\
\text { year period }\end{array}$ & 0.50 & 1.00 & - \\
\hline \multicolumn{5}{|c|}{ Time dependent dummy variables } \\
\hline COMT & $\begin{array}{l}\text { Time-dependent dummy that equals } 1 \text { when the patent is } \\
\text { commercialized and } 0 \text { otherwise. }\end{array}$ & 0.61 & 0.49 & - \\
\hline COMACQT & $\begin{array}{l}\text { Time-dependent dummy that equals } 1 \text { when the patent is acquired, } \\
\text { and } 0 \text { otherwise. }\end{array}$ & 0.06 & 0.25 & - \\
\hline COMLICT & $\begin{array}{l}\text { Time-dependent dummy that equals } 1 \text { when the patent is licensed, } \\
\text { and } 0 \text { otherwise. }\end{array}$ & 0.06 & 0.24 & - \\
\hline COMORIGT & $\begin{array}{l}\text { Time-dependent dummy that equals } 1 \text { when the patent is } \\
\text { commercialized in the original firm and } 0 \text { otherwise. }\end{array}$ & 0.45 & 0.50 & - \\
\hline COMNEWT & $\begin{array}{l}\text { Time-dependent dummy that equals } 1 \text { when the patent is } \\
\text { commercialized in a new firm and } 0 \text { otherwise. }\end{array}$ & 0.09 & 0.28 & - \\
\hline$A L V a n d F T$ & $\begin{array}{l}\text { Time-dependent dummy that equals } 1 \text { when the acquired/ licensed } \\
\text { patent includes variable and fixed fees, and } 0 \text { otherwise. }\end{array}$ & 0.04 & 0.20 & - \\
\hline$A L V o r F T$ & $\begin{array}{l}\text { Time-dependent dummy that equals } 1 \text { when the acquired/ licensed } \\
\text { patent includes variable or fixed fees, and } 0 \text { otherwise. }\end{array}$ & 0.08 & 0.27 & $?$ \\
\hline ALonlyVT & $\begin{array}{l}\text { Time-dependent dummy that equals } 1 \text { when the patent is acquired } \\
\text { / licensed and includes only variable fees, and } 0 \text { otherwise. }\end{array}$ & 0.03 & 0.16 & $?$ \\
\hline ALonlyFT & $\begin{array}{l}\text { Time-dependent dummy that equals } 1 \text { when the patent is acquired } \\
\text { / licensed and includes only fixed fees, and } 0 \text { otherwise. }\end{array}$ & 0.06 & 0.23 & $?$ \\
\hline \multicolumn{5}{|c|}{ Time independent dummy variables } \\
\hline COM & $\begin{array}{l}\text { Dummy that equals } 1 \text { if the patent is commercialized and } 0 \\
\text { otherwise. }\end{array}$ & 0.61 & 0.49 & - \\
\hline COMACQ & $\begin{array}{l}\text { Dummy that equals } 1 \text { if the patent is acquired, and } 0 \text { otherwise } \\
\text { (only first choice). }\end{array}$ & 0.02 & 0.15 & - \\
\hline COMLIC & $\begin{array}{l}\text { Dummy that equals } 1 \text { if the patent is licensed, and } 0 \text { otherwise } \\
\text { (only first choice). }\end{array}$ & 0.05 & 0.22 & - \\
\hline COMORIG & $\begin{array}{l}\text { Dummy that equals } 1 \text { if the patent is commercialized in the } \\
\text { original firm, and } 0 \text { otherwise (only first choice). }\end{array}$ & 0.45 & 0.50 & - \\
\hline COMNEW & $\begin{array}{l}\text { Dummy that equals } 1 \text { if the patent is commercialized in a new } \\
\text { firm and } 0 \text { otherwise (only first choice). }\end{array}$ & 0.08 & 0.27 & - \\
\hline$D E F$ & $\begin{array}{l}\text { Dummy that equals } 1 \text { if the patent is a pure defensive patent, and } \\
0 \text { otherwise }\end{array}$ & 0.02 & 0.13 & - \\
\hline \multicolumn{5}{|c|}{ Control variables } \\
\hline FIRMI & $\begin{array}{l}\text { Dummy taking the value of } 1 \text { for medium-sized firms (101-1000 } \\
\text { employees), and } 0 \text { otherwise. }\end{array}$ & 0.13 & 0.34 & \\
\hline FIRM2 & $\begin{array}{l}\text { Dummy taking the value of } 1 \text { for small firms (11-100 employees), } \\
\text { and } 0 \text { otherwise. }\end{array}$ & 0.23 & 0.42 & \\
\hline FIRM3 & $\begin{array}{l}\text { Dummy taking the value of } 1 \text { for micro companies (2-10 } \\
\text { employees), and } 0 \text { otherwise. }\end{array}$ & 0.16 & 0.37 & \\
\hline UNIV & Dummy that equals 1 for university patents, and 0 otherwise. & 0.04 & 0.19 & \\
\hline SIMILAR & $\begin{array}{l}\text { Dummy taking the value of } 1 \text { if the inventors have more similar } \\
\text { (competitive) patents. }\end{array}$ & 0.41 & 0.49 & \\
\hline$I N V N M B R$ & Number of inventors of the patent. & 1.34 & 0.66 & \\
\hline OWNER & Percent of the patent owned by the inventors. & 65.2 & 45.2 & \\
\hline$S E X$ & Share of inventors who are females & 0.02 & 0.14 & \\
\hline ETH & $\begin{array}{l}\text { Share of inventors with an ethnical background other than } \\
\text { Western European or North-American }\end{array}$ & 0.03 & 0.16 & \\
\hline \multicolumn{5}{|c|}{ Instrument variables in the commercialization equation } \\
\hline KOMPL & $\begin{array}{l}\text { Dummy that equals } 1 \text { if complementary patents are needed to } \\
\text { create a product, and } 0 \text { otherwise }\end{array}$ & 0.23 & 0.42 & \\
\hline GOVFIN & Percent of R\&D financed by government & 7.69 & 21.1 & \\
\hline PRIVFIN & Percent of $R \& D$ financed by private venture capital & 3.14 & 14.4 & \\
\hline OTFIN & Percent of R\&D financed by universities/research foundations & 2.73 & 14.4 & \\
\hline
\end{tabular}

Note: A "T" in the end of the variable denotation indicates a time-dependent dummy variable. 
Table 8. Basic Cox estimations of the renewal decision.

\begin{tabular}{|c|c|c|c|c|c|}
\hline \multicolumn{2}{|c|}{ Dependent variable: $E X P T$} & \multicolumn{4}{|c|}{ Statistical model: Cox proportional hazard model with left-truncation } \\
\hline Explanatory variables & Model I & Model II & Model III & Model IV & Model V \\
\hline$C O M T$ & "----- & $0.51 * * *$ & $0.52 * * *$ & ------ & 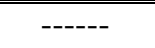 \\
\hline COM & ----- & ------ & ------ & $0.45 * * *$ & $0.46 * * *$ \\
\hline$D E F$ & ------ & $0.27 * *$ & $0.27 * *$ & $0.24 * *$ & $0.24 * * *$ \\
\hline$Q U A L$ & $0.84 * *$ & ------ & $0.86 * *$ & ------ & $0.87 *$ \\
\hline FIRMI & $0.24 * * *$ & $0.22 * * *$ & $0.24 * * *$ & $0.22 * * *$ & $0.23 * * *$ \\
\hline FIRM2 & $0.43 * * *$ & $0.44 * * *$ & $0.46 * * *$ & $0.45 * * *$ & $0.46 * * *$ \\
\hline FIRM3 & $0.56 * * *$ & $0.60 * * *$ & $0.62 * * *$ & $0.62 * * *$ & $0.64 * *$ \\
\hline UNIV & 1.07 & 0.93 & 0.96 & 0.90 & 0.93 \\
\hline SIMILAR & $0.73 * * *$ & $0.81 *$ & 0.82 & 0.83 & 0.84 \\
\hline$I N V N M B R$ & 0.99 & 0.97 & 0.98 & 0.97 & 0.98 \\
\hline OWNER & $0.99 * *$ & $0.99 * *$ & $0.99 * *$ & $0.99 * *$ & $0.99 * *$ \\
\hline SEX & $0.52 *$ & 0.55 & 0.53 & 0.55 & -0.53 \\
\hline ETH & 1.28 & 1.21 & 1.21 & 1.21 & 1.21 \\
\hline Region dummies & Yes & Yes & Yes & Yes & Yes \\
\hline Technology dummies & Yes & Yes & Yes & Yes & Yes \\
\hline Time dummies & Yes & Yes & Yes & Yes & Yes \\
\hline Log-likelihood & -1246.0 & -1231.6 & -1229.1 & -1224.5 & -1222.4 \\
\hline Likelihood-ratio test & $127.9 * * *$ & $156.7 * * *$ & $161.5 * * *$ & $170.9 * * *$ & $175.1 * * *$ \\
\hline
\end{tabular}

Note: The total number of observations is 867,482 of which are right-censored. The estimated figures are hazard ratios. $* * * * *$ and $*$ indicate significance at the 1,5 and 10 percent level, respectively. Region, technology and time dummies are not shown, but are available from the author upon request. 
Table 9. Estimations of the commercialization decision.

\begin{tabular}{|c|c|c|c|c|c|c|}
\hline Dependent variable & \multicolumn{3}{|c|}{ COMT } & \multicolumn{3}{|c|}{$C O M$} \\
\hline Statistical model & \multicolumn{3}{|c|}{ Accelerated failure time model } & \multicolumn{3}{|c|}{ Probit model } \\
\hline Explanatory & Model & Model & Model & Model & Model & Model \\
\hline variables & VI-a & VI-b & VI-c & VII-a & VII-b & VII-c \\
\hline$\overline{Q Q U A L}$ & -0.31 & $-0.42 * *$ & $-0.39 * *$ & $0.10 * *$ & $0.12 * *$ & $0.12 * *$ \\
\hline FIRM1 & -1.30 & -1.30 & -1.14 & 0.28 & 0.29 & 0.25 \\
\hline FIRM2 & $-1.68 * *$ & $-1.54 * *$ & $-1.46 * *$ & $0.33 * *$ & $0.31 *$ & $0.29 *$ \\
\hline FIRM3 & $-2.05 * * *$ & $2.18 * * *$ & $2.16 * * *$ & $0.49 * * *$ & $0.54 * * *$ & $0.53 * * *$ \\
\hline GOVFIN & $0.046 * * *$ & $0.040 * * *$ & $0.041 * * *$ & $-9.5 \mathrm{E}-3 * * *$ & $-9.0 \mathrm{E}-3 * * *$ & $-9.2 \mathrm{E}-3 * * *$ \\
\hline PRIVFIN & $-5.3 \mathrm{E}-3$ & $-4.8 \mathrm{E}-3$ & $-5.2 \mathrm{E}-3$ & $2.2 \mathrm{E}-3$ & $2.9 \mathrm{E}-3$ & 2.7 E-3 \\
\hline OTHERFIN & 0.017 & 0.020 & 0.021 & $-2.9 \mathrm{E}-3$ & $-3.3 \mathrm{E}-3$ & $-3.4 \mathrm{E}-3$ \\
\hline UNIV & $3.21 * *$ & $4.04 * * *$ & $3.94 * * *$ & $-0.48 *$ & $-0.74 * *$ & $-0.71 * *$ \\
\hline SIMILAR & -0.53 & -0.45 & -0.55 & 0.14 & 0.12 & 0.13 \\
\hline$K O M P L$ & $-1.51 * * *$ & $-1.60 * * *$ & $-1.52 * * *$ & $0.40 * * *$ & $0.46 * * *$ & $0.45 * * *$ \\
\hline$I N V N M B R$ & 0.41 & 0.34 & 0.32 & -0.068 & -0.068 & -0.067 \\
\hline OWNER & $7.1 \mathrm{E}-4$ & $5.0 \mathrm{E}-4$ & $-1.2 \mathrm{E}-4$ & $1.3 \mathrm{E}-3$ & $1.2 \mathrm{E}-3$ & $1.1 \mathrm{E}-3$ \\
\hline$S E X$ & -1.60 & -1.68 & -1.55 & 0.33 & 0.33 & 0.31 \\
\hline ETH & 0.14 & 0.19 & 0.023 & -0.18 & -0.22 & -0.18 \\
\hline Region dummies & Yes & No & Yes & Yes & No & Yes \\
\hline Techn. dummies & No & Yes & Yes & No & Yes & Yes \\
\hline Time dummies & Yes & Yes & Yes & Yes & Yes & Yes \\
\hline Log-likelihood & -1945.8 & -1936.0 & -1933.1 & -536.5 & -527.7 & 525.8 \\
\hline Likelihood-ratio test & $103.0 * * *$ & $122.6 * * *$ & $128.0 * * *$ & $89.2 * * *$ & $106.8 * * *$ & $110.6 * * *$ \\
\hline
\end{tabular}


Table 10. Extended Cox Model of the renewal decision with endogenous commercialization.

\begin{tabular}{|c|c|c|c|c|c|c|c|c|}
\hline \multirow{2}{*}{$\begin{array}{l}\text { Model } \\
\text { Dependent } \\
\text { variable }\end{array}$} & \multicolumn{2}{|c|}{ Model VIII } & \multirow{2}{*}{$\begin{array}{c}\begin{array}{c}\text { Model } \\
\text { IX }\end{array} \\
E X P T\end{array}$} & \multicolumn{2}{|c|}{ Model X } & \multirow{2}{*}{$\begin{array}{c}\text { Model } \\
\text { XI } \\
E X P T\end{array}$} & \multicolumn{2}{|c|}{ Model XII } \\
\hline & $C O M$ & $E X P T$ & & $C O M$ & $E X P T$ & & $C O M$ & $E X P T$ \\
\hline Statistical model & Probit & Cox & Cox & Probit & Cox & Cox & Probit & Cox \\
\hline $\begin{array}{l}\text { Explanatory } \\
\text { variables }\end{array}$ & $1^{\text {st }}$ step & $2^{\text {nd }}$ step & $2^{\text {nd }}$ step & $1^{\text {st }}$ step & $2^{\text {nd }}$ step & $2^{\text {nd }}$ step & $1^{\text {st }}$ step & $2^{\text {nd }}$ step \\
\hline Pred $(C O M)$ & ------ & $0.15 * * *$ & $0.11 * * *$ & ------ & 0.32 & $0.16 * *$ & ------ & $0.12 * * *$ \\
\hline$D E F$ & ------ & 0.45 & 0.45 & ------ & 0.42 & 0.43 & ------ & 0.45 \\
\hline$Q U A L$ & $0.12 * *$ & 0.91 & ------ & $0.12 * *$ & 0.88 & ------ & $0.12 * *$ & 0.91 \\
\hline FIRMI & 0.25 & $0.29 * * *$ & $0.29 * * *$ & 0.28 & $0.26 * * *$ & $0.28 * * *$ & 0.30 & $0.29 * * *$ \\
\hline FIRM2 & $0.29 *$ & $0.54 * * *$ & $0.55 * * *$ & $0.35 * *$ & $0.49 * * *$ & $0.53 * * *$ & $0.31 *$ & $0.56 * *$ \\
\hline FIRM3 & $0.53 * * *$ & 0.82 & 0.85 & $0.56 * * *$ & 0.70 & 0.79 & $0.55 * * *$ & 0.86 \\
\hline UNIV & $-0.71 * *$ & 0.76 & 0.71 & -0.79 & 0.88 & 0.75 & $-0.56 *$ & 0.71 \\
\hline SIMILAR & 0.13 & 0.88 & 0.89 & $0.17 *$ & 0.83 & 0.87 & $0.19 *$ & 0.89 \\
\hline$I N V N M B R$ & -0.067 & 0.93 & 0.92 & -0.07 & 0.95 & 0.93 & -0.073 & 0.92 \\
\hline OWNER & $1.1 \mathrm{E}-3$ & $0.99 * *$ & $0.99 * *$ & $1.0 \mathrm{E}-4$ & $0.99 * *$ & $0.99 * *$ & $1.1 \mathrm{E}-3$ & $0.99 * *$ \\
\hline SEX & 0.31 & 0.61 & 0.64 & 0.22 & 0.57 & 0.62 & 0.27 & 0.60 \\
\hline ETH & -0.18 & 1.07 & 1.05 & -0.26 & 1.12 & 1.05 & -0.19 & 1.06 \\
\hline GOVFIN & $-0.01 * * *$ & ------ & ----- & ------ & ----- & ----- & $-0.01 * * *$ & ----- \\
\hline PRIVFIN & 0.003 & ----- & ------ & ------ & ------ & ------ & 0.003 & ------ \\
\hline OTHERFIN & -0.003 & ------ & ------ & ------ & ------ & ------ & -0.003 & ------ \\
\hline$K O M P L$ & $0.45 * * *$ & ------ & ------ & $0.45 * * *$ & ------ & ----- & ------ & ------ \\
\hline No. of instruments & ------ & 4 & 5 & ------ & 1 & 2 & ------ & 3 \\
\hline Region dummies & Yes & Yes & Yes & Yes & Yes & Yes & Yes & Yes \\
\hline Techn. dummies & Yes & Yes & Yes & Yes & Yes & Yes & Yes & Yes \\
\hline Time dummies & Yes & Yes & Yes & Yes & Yes & Yes & Yes & Yes \\
\hline Log-likelihood & -525.8 & -1240.2 & -1241.0 & -532.4 & -1243.9 & -1245.2 & -532.7 & -1241.3 \\
\hline $\begin{array}{l}\text { Likelihood-ratio } \\
\text { test }\end{array}$ & $110.6 * * *$ & $139.5 * * *$ & $137.8 * * *$ & $97.4 * * *$ & $132.1 * * *$ & $129.4 * * *$ & $117.8 * * *$ & $137.2 * * *$ \\
\hline
\end{tabular}

Note: The total number of observations is 867,482 of which are right-censored in the Cox model. Models VIII and IX have identical $1^{\text {st }}$ step probit model specifications. This is also the case for Models X and XI. The estimated figures in the Cox model are hazard ratios. ***,** and $*$ indicate significance at the 1,5 and 10 percent level, respectively. Region, technology and time dummies are not shown, but are available from the author upon request. 
Table 11. Cox estimations of the renewal decision with different commercialization modes.

\begin{tabular}{|c|c|c|c|c|c|}
\hline Dependent variable: & \multicolumn{5}{|c|}{ "Statistical model: Cox proportional hazard model with left-truncation } \\
\hline Explanatory variables & Model XIII & Model XIV & Model XV & Model XVI & Model XVII \\
\hline COMACQT & 0.78 & 0.78 & 0.80 & ------ & $\begin{array}{l}------ \\
\end{array}$ \\
\hline COMLICT & $0.47 * * *$ & $0.50 * * *$ & $0.53 * * *$ & ------ & ------ \\
\hline COMORIGT & $0.51 * * *$ & $0.52 * * *$ & $0.47 * * *$ & ------ & ------ \\
\hline COMNEWT & $0.44 * * *$ & $0.44 * * *$ & $0.52 * * *$ & ------ & ------ \\
\hline COMACQ & ------ & ------ & ------ & $0.43 * *$ & $0.41 * *$ \\
\hline COMLIC & ------ & ------ & ------ & $0.46 * * *$ & $0.47 * * *$ \\
\hline COMORIG & ------ & ------ & ----- & $0.46 * * *$ & $0.47 * * *$ \\
\hline COMNEW & ------ & ------ & ------ & $0.38 * * *$ & $0.49 * * *$ \\
\hline$D E F$ & $0.27 * *$ & $0.27 * *$ & $0.30 * *$ & $0.26 * *$ & $0.26 * *$ \\
\hline$Q U A L$ & ------ & $0.86 * *$ & $0.83 * *$ & ------ & $0.86 * *$ \\
\hline FIRMI & $0.22 * * *$ & $0.24 * * *$ & ------ & $0.27 * * *$ & $0.28 * * *$ \\
\hline FIRM2 & $0.44 * * *$ & $0.45 * * *$ & ------ & $0.49 * * *$ & $0.50 * * *$ \\
\hline FIRM3 & $0.59 * * *$ & $0.62 * * *$ & ------ & $0.64 * *$ & $0.65 * *$ \\
\hline UNIV & 0.94 & 0.98 & 1.32 & 0.96 & 0.99 \\
\hline SIMILAR & 0.82 & 0.83 & 0.79 & 0.84 & 0.85 \\
\hline$I N V N M B R$ & 0.98 & 0.99 & 0.96 & 0.96 & 0.98 \\
\hline OWNER & $0.99 * *$ & $0.99 * *$ & $1.01 *$ & $0.99 *$ & 1.00 \\
\hline$S E X$ & 0.56 & 0.55 & 0.59 & 0.55 & 0.53 \\
\hline ETH & 1.25 & 1.23 & 1.27 & 1.24 & 1.27 \\
\hline Region dummies & Yes & Yes & Yes & Yes & Yes \\
\hline Technology dummies & Yes & Yes & Yes & Yes & Yes \\
\hline Time dummies & Yes & Yes & Yes & Yes & Yes \\
\hline Log-likelihood & -1229.7 & -1227.4 & -1240.0 & -1268.9 & -1266.4 \\
\hline Likelihood-ratio test & $160.5 * * *$ & $165.1 * * *$ & $139.8 * * *$ & $189.3 * * *$ & $194.2 * * *$ \\
\hline
\end{tabular}

Note: The total number of observations is 867,482 of which are right-censored. The estimated figures are hazard ratios. $* * *, * *$ and $*$ indicate significance at the 1,5 and 10 percent level, respectively. Region, technology and time dummies are not shown, but are available from the author upon request. 
Table 12. Cox estimations of the renewal decision with different contract terms for acquired and licensed patents.

\begin{tabular}{|c|c|c|c|c|c|c|}
\hline $\begin{array}{l}\text { Dependent variable: } \\
E X P T\end{array}$ & \multicolumn{6}{|c|}{ Statistical model: Cox hazard model with left-truncation } \\
\hline Explanatory variables & $\begin{array}{l}\text { Model } \\
\text { XVIII }\end{array}$ & $\begin{array}{l}\text { Model } \\
\text { IX }\end{array}$ & $\begin{array}{c}\text { Model } \\
\text { XX }\end{array}$ & $\begin{array}{c}\text { Model } \\
\text { XXI }\end{array}$ & $\begin{array}{c}\text { Model } \\
\text { XXII }\end{array}$ & $\begin{array}{l}\text { Model } \\
\text { XXIII }\end{array}$ \\
\hline ALVandFT & $0.39 * * *$ & $0.38 * * *$ & $0.42 * *$ & $0.38 * * *$ & $0.39 * * *$ & $0.38 * * *$ \\
\hline ALVorFT & 0.77 & 0.75 & 0.80 & 0.76 & ------ & ------ \\
\hline ALonlyVT & ------ & ------ & ------ & ------ & 0.74 & 0.70 \\
\hline ALonlyFT & ------ & ------ & ------ & ------ & 0.78 & 0.78 \\
\hline COMORIGT & $0.51 * * *$ & $0.51 * * *$ & $0.47 * * *$ & $0.51 * * *$ & $0.51 * * *$ & $0.51 * * *$ \\
\hline COMNEWT & $0.44 * * *$ & $0.43 * * *$ & $0.52 * * *$ & $0.41 * * *$ & $0.44 * * *$ & $0.43 * * *$ \\
\hline$D E F$ & $0.26 * *$ & $0.26 * *$ & $0.29 * *$ & $0.25 * *$ & $0.26 * *$ & $0.26 * *$ \\
\hline$Q U A L$ & $0.86 * *$ & ------ & $0.83 * *$ & $0.85 * *$ & $0.86 * *$ & ------ \\
\hline FIRMI & $0.23 * * *$ & $0.22 * * *$ & ----- & $0.36 * * *$ & $0.23 * * *$ & $0.22 * * *$ \\
\hline FIRM2 & $0.46 * * *$ & $0.44 * * *$ & ------ & $0.61 * * *$ & $0.45 * * *$ & $0.43 * * *$ \\
\hline FIRM3 & $0.62 * *$ & $0.60 * * *$ & ------ & $0.71 * *$ & $0.62 * *$ & $0.60 * * *$ \\
\hline UNIV & 0.98 & 0.95 & 1.32 & ------ & 0.98 & 0.95 \\
\hline SIMILAR & 0.84 & 0.83 & $0.79 *$ & ------ & 0.84 & 0.83 \\
\hline$I N V N M B R$ & 0.99 & 0.98 & 0.96 & ------ & 0.99 & 0.98 \\
\hline OWNER & $0.99 * *$ & $0.99 * *$ & $1.01 *$ & ------ & $0.99 * *$ & $0.99 * *$ \\
\hline$S E X$ & 0.55 & 0.57 & 0.59 & ------ & 0.55 & 0.57 \\
\hline$E T H$ & 1.22 & 1.24 & 1.26 & ----- & 1.22 & 1.25 \\
\hline Regional dummies & Yes & Yes & Yes & Yes & Yes & Yes \\
\hline Technology dummies & Yes & Yes & Yes & Yes & Yes & Yes \\
\hline Time dummies & Yes & Yes & Yes & Yes & Yes & Yes \\
\hline \multicolumn{7}{|c|}{ Hazard ratios between different groups } \\
\hline ALVandFT / ALVorFT & $0.51 *$ & 0.51 & 0.53 & $0.49 *$ & ------ & ------ \\
\hline ALVandFT / ALonlyVT & ------ & ------ & ------ & ------ & 0.53 & 0.54 \\
\hline ALVandFT / ALonlyFT & ------ & ------ & ------ & ------ & 0.51 & 0.49 \\
\hline Log-likelihood & -1226.4 & -1228.8 & -1239.0 & -1231.4 & -1226.4 & -1228.6 \\
\hline Likelihood-ratio test & $167.1 * * *$ & $162.3 * * *$ & $141.8 * * *$ & $157.1 * * *$ & $167.1 * * *$ & $162.4 * * *$ \\
\hline
\end{tabular}

Note: The total number of observations is 867,482 of which are right-censored. The estimated figures are hazard ratios. $* * *, * *$ and $*$ indicate significance at the 1,5 and 10 percent level, respectively. Region, technology and time dummies are not shown, but are available from the author upon request. 